\title{
Abrogation of TGF- $\beta$ signaling enhances chemokine production and correlates with prognosis in human breast cancer
}

\author{
Brian Bierie, ${ }^{1}$ Christine H. Chung,, ${ }^{1,2,3,4}$ Joel S. Parker, ${ }^{5}$ Daniel G. Stover, ${ }^{2}$ Nikki Cheng, $^{1}$ \\ Anna Chytil, ${ }^{4}$ Mary Aakre, ${ }^{4}$ Yu Shyr, ${ }^{4,6}$ and Harold L. Moses ${ }^{1,2,4}$ \\ 1Department of Cancer Biology, ${ }^{2}$ Department of Medicine, ${ }^{3}$ Division of Hematology/Oncology, and \\ ${ }^{4}$ Vanderbilt-Ingram Cancer Center, Vanderbilt University, Nashville, Tennessee, USA. ${ }^{5}$ Expression Analysis Inc., Durham, North Carolina, USA. \\ ${ }^{6}$ Department of Biostatistics, Vanderbilt University, Nashville, Tennessee, USA.
}

\begin{abstract}
In human breast cancer, loss of carcinoma cell-specific response to TGF- $\beta$ signaling has been linked to poor patient prognosis. However, the mechanisms through which TGF- $\beta$ regulates these processes remain largely unknown. In an effort to address this issue, we have now identified gene expression signatures associated with the TGF- $\beta$ signaling pathway in human mammary carcinoma cells. The results strongly suggest that TGF- $\beta$ signaling mediates intrinsic, stromal-epithelial, and host-tumor interactions during breast cancer progression, at least in part, by regulating basal and oncostatin $\mathrm{M}$-induced CXCL1, CXCL5, and CCL20 chemokine expression. To determine the clinical relevance of our results, we queried our TGF- $\beta$-associated gene expression signatures in 4 human breast cancer data sets containing a total of 1,319 gene expression profiles and associated clinical outcome data. The signature representing complete abrogation of TGF- $\beta$ signaling correlated with reduced relapse-free survival in all patients; however, the strongest association was observed in patients with estrogen receptor-positive (ER-positive) tumors, specifically within the luminal A subtype. Together, the results suggest that assessment of TGF- $\beta$ signaling pathway status may further stratify the prognosis of ER-positive patients and provide novel therapeutic approaches in the management of breast cancer.
\end{abstract}

\section{Introduction}

TGF- $\beta$ ligands are key factors in the regulation of tumor initiation, progression, and metastasis. In human breast cancer, alterations in the carcinoma cell response to TGF- $\beta$ signaling have been linked to tumor progression. It has been shown, using tissues from women with mammary epithelial hyperplasia lacking atypia, that decreased immunohistochemical staining for the type II TGF- $\beta$ receptor (T $\beta$ RII) correlated with an increased risk of developing invasive breast cancer (1). In this study, a 3-fold reduction in the number of T $\beta$ RII-positive carcinoma cells correlated with an approximately 3 -fold increase in the risk of developing subsequent invasive breast cancer (1). The loss of T $\beta$ RII expression has also been correlated with high-grade human carcinoma in situ and invasive breast cancer (2). These observations are consistent with previously reported data demonstrating that human breast cancer cells with deficient T $\beta$ RII expression were more tumorigenic than the same tumor cells in which the receptor was experimentally reintroduced (3). Notably, it has been shown that loss of TGFBR2 gene expression can occur through promoter hypermethylation in human breast carcinoma cells (4). In addition, the presence of an activating $\mathrm{T} 29 \rightarrow \mathrm{C}$ polymorphism in the TGFB1 gene increased the serum levels of TGF- $\beta 1$ ligand and correlated with a reduced risk of developing breast cancer (5).

Authorship note: Brian Bierie and Christine H. Chung contributed equally to this work.

Conflict of interest: The authors have declared that no conflict of interest exists.

Nonstandard abbreviations used: EMT, epithelial-mesenchymal transition; ER, estrogen receptor; MFS, metastasis-free survival; OSM, oncostatin M; PyVmT, polyoma virus middle T antigen; RFS, relapse-free survival; T $\beta$ RII, type II TGF- $\beta$ receptor. Citation for this article: J. Clin. Invest. 119:1571-1582 (2009). doi:10.1172/JCI37480.
However, the effect of TGF- $\beta$ signaling is known to be context specific; TGF- $\beta$ is thought to be an early tumor suppressor and late tumor promoter during disease progression. Recently, gene expression profiling was used to identify a signature in established human cell lines indicative of TGF- $\beta$ stimulation (6). In this study, the TGF- $\beta$ response gene expression signature was shown to predict for increased lung metastasis in human breast cancer, whereas no significant correlation was made with metastasis to bone. Further, the correlation between TGF- $\beta$ signaling and increased lung metastasis was more significant in association with estrogen receptor-negative (ER-negative) tumors. Interestingly, this effect was functionally validated using late-stage breast cancer cells, originally derived from a pleural effusion, wherein it was shown that TGF- $\beta$ signaling primed the cells for lung metastasis through upregulation of angiopoietin-like 4 (ANGPTL4) gene expression (6). The context specificity is further supported by a recent finding that there is a synergy between TGF- $\beta$ and other transforming oncogenes such as HER2. Constitutive activation of T $\beta R I$ in the presence of HER 2 amplification enhanced cell survival and migration and desensitized the cells to trastuzumab, while the signature was associated again with ER-negative tumors (7). This may partially explain the correlation among TGF- $\beta$ signaling, ER negativity, and poor prognosis, since a significant number of ER-negative tumors have HER2 amplification $(8,9)$. To experimentally determine the impact of TGF- $\beta$ signaling on tumor initiation, progression, and metastasis in vivo, we and others have used several mouse models of mammary tumorigenesis with engineered alterations in TGF- $\beta$ pathway signaling components. Using this approach, it was shown that enhanced TGF- $\beta$ signaling could suppress early tumor progression $(10,11)$. The observations related to suppression of tumor growth were later paralleled by results obtained through 
expression of a dominant negative type II TGF- $\beta$ receptor in mammary epithelium (MMTV-DNIIR) (12). However, expression of the MMTV-DNIIR transgene also resulted in decreased carcinoma cell invasion (12). This correlated with previous results demonstrating that systemic inhibition of TGF- $\beta$ signaling, through administration of an Fc-conjugated T $\beta$ RII (Fc:T $\beta$ RII), resulted in resistance to spontaneous metastasis in the MMTV-Neu mouse mammary tumor model and in a model in which metastasis was achieved through tail vein injection of carcinoma cells (13). Several subsequent studies further illustrated the link between enhanced TGF- $\beta$ signaling and enhanced metastasis in vivo (14-17). Together, the results suggested that secretion of TGF- $\beta$ and thereby stimulation of all cells in the mammary tumor microenvironment could result in enhanced tumor metastasis, while the effect on tumor growth was context dependent. Further, the data suggested that at least some of the invasion and metastasis effects were dependent upon direct carcinoma cell-specific responses to TGF- $\beta$ stimulation in vivo. However, it has now been shown, in the MMTV-polyoma virus middle $\mathrm{T}$ antigen (MMTV-PyVmT) model of mammary tumorigenesis, that there may be a substantial difference between attenuation and complete abrogation of TGF- $\beta$ signaling with regard to the regulation of metastasis (18). This study was the first to clearly demonstrate in vivo that a complete loss of TGF- $\beta$ response in mammary carcinoma cells could significantly increase the occurrence of spontaneous pulmonary metastases (18).

In recent studies, we have been able to further validate pulmonary metastasis increases when carcinoma cell-specific TGF- $\beta$ signaling is ablated (19). Further, we have identified a decrease in apoptosis, increased abundance of adjacent smooth muscle actin-positive fibrovasculature stroma, increased carcinoma cell heterogeneity, and increased inflammatory gene expression that correlated with bone marrow-derived myeloid cell infiltration in T $\beta$ RII-ablated mammary carcinoma tissues when compared with controls (19, $20)$. However, it was difficult to understand precisely how TGF- $\beta$ regulated these effects due to the complex nature of our observed compound phenotypic differences. Therefore, to address the mechanistic role for TGF- $\beta$ signaling associated with regulation of tumorigenesis in this context, we have now isolated and established multiple parallel, independent polyclonal carcinoma cell lines from control and T $\beta$ RII-ablated MMTV-PyVmT-derived tumor models $\left[\mathrm{T} \beta \mathrm{RII}{ }^{(\mathrm{fl} / \mathrm{fl} ; \mathrm{PY})}\right.$ and T $\beta \mathrm{RII}{ }^{(\mathrm{WKO} ; \mathrm{PY})}$ respectively] (19). The two models differ in the ability to respond to TGF- $\beta$ signaling. The T $\beta \mathrm{RII} \mathrm{I}^{(\mathrm{fl} / \mathrm{fl} ; \mathrm{PY})}$ model expresses T $\beta$ RII, while the T $\beta$ RII (WKO;PY) model is deficient in the ability to express T $\beta$ RII as a result of Cre-mediated deletion of exon 2 from the Tgfbr 2 gene. Using these cell lines, we performed microarray analyses to determine the differences in gene expression between the models and in response to TGF- $\beta$ stimulation. These analyses were conducted in an effort to identify mechanisms that mediate TGF- $\beta$-dependent regulation of tumorigenesis in vivo, and the results indicated that a major function for TGF- $\beta$ signaling is the regulation of chemokine expression.

The strength of functional analyses associated with mouse modeling is balanced by limitations in interpretation of individual observations with regard the direct impact on human disease. However, molecular profiling offers the ability to directly assess the prognostic value of results obtained from genome scale pathway interactions identified in experimental model systems. The power associated with molecular profiling of tumor subtypes and clinical outcome has been highlighted in recent years $(8,9,21)$. We have been able to obtain high-quality microarray profiles from 1,319 human breast cancer tissues with well-documented clinical data related to tumor size, LN involvement, ER status, treatment regimen, and time of relapse detection over a 10-year period if present (Gene Expression Omnibus ID: GSE10886, GSE4922, GSE6532, and GSE2845) (22-28). Using the clinical data and gene expression profiles represented by these 4 data sets, we have been able to determine that the signature associated with our T $\beta$ RII-deficient carcinoma cells predicted poor relapse-free survival (RFS). Further, the patients presenting with $\mathrm{ER}^{+}$or luminal A subtype breast cancer demonstrated a significant increase in the risk of recurrence if they had a gene expression profile that was similar to the T $\beta$ RII-deficient carcinoma cell signature at the time of diagnosis.

\section{Results}

PyVmT mammary carcinoma cells exhibit an epithelial-mesenchymal transition in response to TGF- $\beta$ stimulation. To determine functional and molecular roles for TGF- $\beta$ signaling in mammary carcinoma cells, we established individually derived polyclonal carcinoma cell lines from T $\beta R \mathrm{RII}^{(\mathrm{fl} / \mathrm{fl} ; \mathrm{PY})}$ control and T $\beta \mathrm{RII} \mathrm{I}^{(\mathrm{WKO} ; \mathrm{PY})}$ mammary tumors. Three of the cell lines from each model were selected for analysis. The cell lines were screened for T $\beta$ RII recombination (Figure 1A). The $\mathrm{T} \beta \mathrm{RII}{ }^{(\mathrm{fl} / \mathrm{fl} ; \mathrm{PY})}$ control cells demonstrated the presence of the floxed allele without any evidence of recombination. The T $\beta$ RII(WKO;PY) cells were $100 \%$ recombined, with no evidence of a loxP-flanked T $\beta$ RII allele. The recombination efficiency was functionally validated using a TGF- $\beta$ growth response assay 24 hours after stimula-

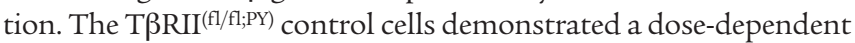
response to TGF- $\beta$ stimulation that resulted in reduced tritiated thymidine incorporation (Figure 1B). As expected, the T $\beta \mathrm{RII}(\mathrm{WKO} ; \mathrm{PY})$ cells did not demonstrate a significant difference in tritiated thymidine incorporation after TGF- $\beta$ treatment. It has recently been shown that some, but not all, epithelial cell lines respond to TGF- $\beta$ with an epithelial-mesenchymal transition (EMT) (29). The EMT process has been linked to increased carcinoma cell motility, invasion, and metastasis (30-33). In vitro, the $\mathrm{T} \beta \mathrm{RII} \mathrm{I}^{(\mathrm{fl} / \mathrm{fl} ; \mathrm{PY})}$ control cell lines were predominantly present in clusters of cells with an epithelial morphology (Figure 1C). In response to TGF- $\beta$, the T $\beta$ RII ${ }^{(\mathrm{fl} / \mathrm{fl} ; \mathrm{PY})}$ control cell lines exhibited an elongated, fibroblast-like morphology and cell scattering - hallmarks of EMT (Figure 1D). The changes in cell morphology correlated with reduced cell-surface tethering of E-cadherin and F-actin (Figure 1, E-H). In TGF- $\beta$-treated cells, E-cadherin appeared to be degraded rather than accumulate in the cytoplasm (Figure 1F). In complete medium, F-actin was detected in the cytoplasm and tethered to the cell membrane (Figure 1G). However, when TGF- $\beta$ was added to the medium, F-actin was predominantly associated with stress fibers in the cytoplasm (Figure $1 \mathrm{H})$. Interestingly, $\mathrm{N}$-cadherin was not significantly upregulated in the EMT-like carcinoma cells after the observed TGF- $\beta$-dependent response (data not shown). Due to the enhanced rate of metastatic spread observed in our T $\beta$ RII(WKO;PY) model, we also hypothesized that the mammary carcinoma cells lacking T $\beta$ RII expression may have an increased sensitivity to growth factors or a predisposition toward spontaneous EMT. However, the rate of growth in response to serum was similar for the $\mathrm{T} \beta \mathrm{RII} \mathrm{I}^{\mathrm{(I} / \mathrm{fl} ; \mathrm{PY})}$ control and $\mathrm{T} \beta \mathrm{RII} \mathrm{I}^{(\mathrm{WKO} ; \mathrm{PY})}$ cell lines. In addition, the T $\beta$ RII(WKO;PY) cells did not exhibit spontaneous EMT under complete culturing conditions or when cultured in the presence of TGF- $\beta$ (Figure 1, I and J). Together, the data indicated that our $\mathrm{T} \beta \mathrm{RII} \mathrm{If}^{(\mathrm{f} / \mathrm{fl} ; \mathrm{PY})}$ control and $\mathrm{T} \beta \mathrm{RII} \mathrm{I}^{(\mathrm{WKO} ; \mathrm{PY})}$ cell lines were suitable for comparison. Further, differences in response to growth factor stimulation or spontaneous EMT could not account for the 
A
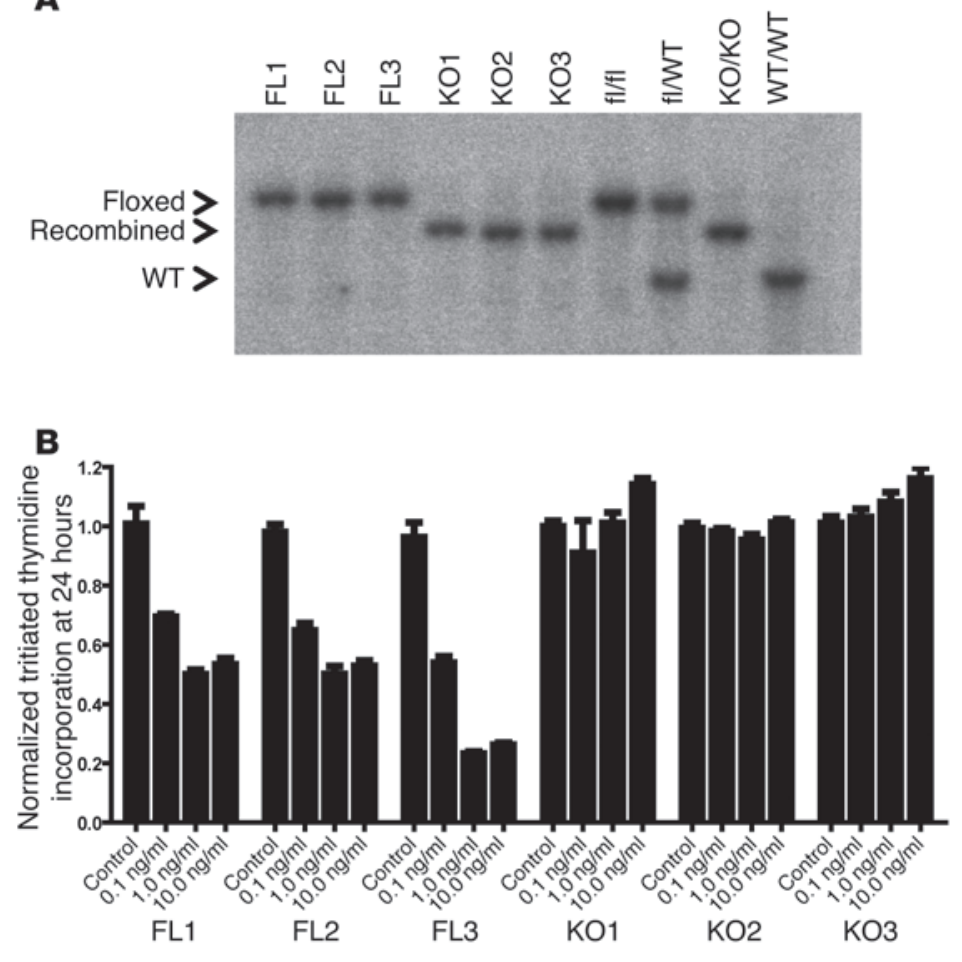
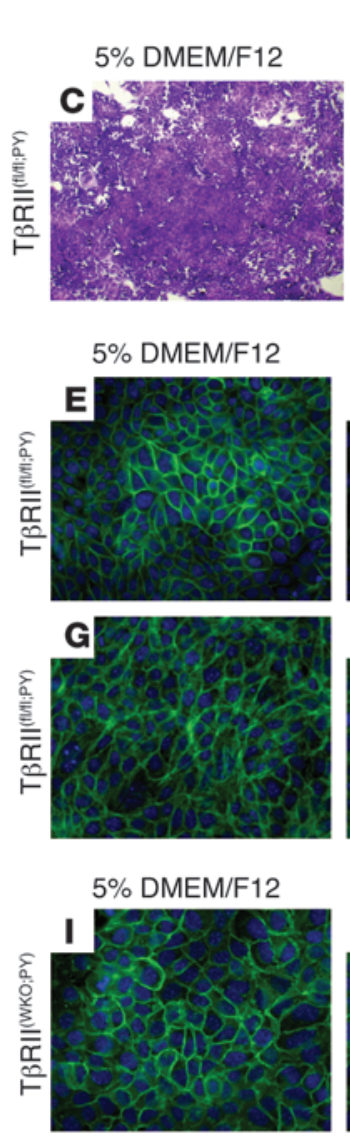

$5 \%$ DMEM/F12 + $10 \mathrm{ng} / \mathrm{ml} \mathrm{TGF}-\beta$

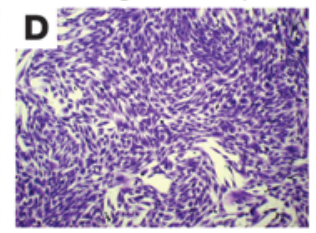

$5 \%$ DMEM/F12 + $10 \mathrm{ng} / \mathrm{ml}$ TGF- $\beta$
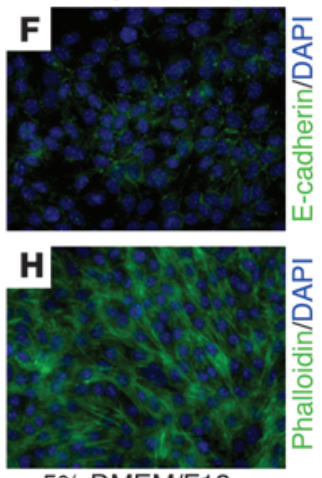

$5 \%$ DMEM/F12 + $10 \mathrm{ng} / \mathrm{ml}$ TGF- $\beta$

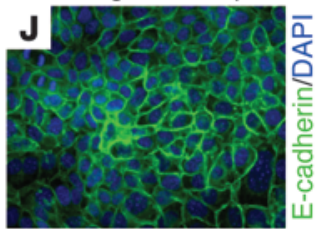

\section{Figure 1}

Recombination of T $\beta$ RII and induction of TGF- $\beta$-dependent EMT in MMTV-PyVmT mammary carcinoma cells. (A) Analysis of Southern blot hybridization demonstrated that the independently derived polyclonal T $\beta$ RIII(f/lfi;PY) control mammary carcinoma cells (FL1, FL2, and FL3; biological replicates) had intact floxed Tgfbr2 alleles, with no evidence of recombination. Alternatively, the independently derived polyclonal T $\beta R \mathrm{II}(\mathrm{WKO} ; \mathrm{PY}$ ) carcinoma cells (KO1, KO2, and KO3; biological replicates) were completely recombined, with no evidence of a remaining floxed Tgfbr2 allele. (B) The growth of $\mathrm{T} \beta \mathrm{RI}^{(\mathrm{fl} / \mathrm{fl} ; \mathrm{PY})}$ control carcinoma cell lines, measured by tritiated thymidine incorporation 24 hours after stimulation, was markedly inhibited by TGF- $\beta$ stimulation, whereas the T $\beta$ RII(WKO;PY) carcinoma cell growth was not altered. Results represent median transformed mean values \pm SEM. (C and D) In response to TGF- $\beta$ stimulation $(10 \mathrm{ng} / \mathrm{ml})$ for 48 hours, the T $\beta R \mathrm{II}^{(\mathrm{fl} / \mathrm{fl} / \mathrm{PY})}$ control carcinoma cells demonstrated consistent changes in morphology and cell scattering that suggested that EMT had occurred (original magnification, $\times 10)$. (E-H) Loss of E-cadherin $(\mathbf{E}$ and $\mathbf{F})$ and changes in F-actin localization from the cell membrane $(\mathbf{G})$ to predominant association with stress fibers $(\mathbf{H})$ further confirmed an EMT-like state in T $\beta$ RII $\left.\right|^{(f / f / f ; P Y)}$ cells that had been treated with $10 \mathrm{ng} / \mathrm{ml}$ of TGF- $\beta$ for 48 hours $(\mathrm{E}-\mathbf{H}$; original magnification, $\times 40)$. (I and $\left.\mathbf{J}\right)$ Loss of TGF- $\beta$ signaling in T $\beta$ RII(WKO;PY) cells did not result in a spontaneous state of EMT, as determined by the presence of membrane-bound E-cadherin, in the presence or absence of TGF- $\beta$ ligand at $10 \mathrm{ng} / \mathrm{ml}$ after 48 hours of stimulation (original magnification, $\times 40$ ).

enhanced metastatic spread observed in the T $\beta \mathrm{RII}(\mathrm{WKO}$;PY) model when compared with the T $\beta \mathrm{RII} \mathrm{I}^{(\mathrm{fl} / \mathrm{fl} ; \mathrm{PY})}$ controls.

Molecular profiling revealed a difference in expression of genes that are known to regulate tumor progression. To understand how TGF- $\beta$ could regulate carcinoma cell-associated gene expression, which ultimately regulates tumor progression and metastasis, we performed Affymetrix microarray analyses. T $\beta R I^{(\mathrm{WKO} ; \mathrm{PY})}, \mathrm{T} \beta \mathrm{RII} \mathrm{I}^{(\mathrm{fl} / \mathrm{fl} ; \mathrm{PY})}$, and TGF- $\beta$-treated T $\beta$ RII ${ }^{(\mathrm{fl} / \mathrm{fl} ; \mathrm{PY})}$ cell lines were hybridized for subsequent analyses. We identified 108 genes that were upregulated and 48 genes that were downregulated in $\mathrm{T} \beta \mathrm{RII} \mathrm{I}^{(\mathrm{WKO} ; \mathrm{PY})}$ cell lines when compared with the T $\beta$ RII ${ }^{(\mathrm{fl} / \mathrm{fl}) \mathrm{PY})}$ controls (Supplemental Table 1; supplemental material available online with this article; doi:10.1172/JCI37480DS1). To determine the genes that were acutely regulated by TGF- $\beta$, we performed pairwise analyses using $\mathrm{T} \beta \mathrm{RII} \mathrm{I}^{\mathrm{( \textrm {f } / \mathrm { fl }} ; \mathrm{PY})}$ mammary carcinoma cells in the presence or absence of TGF- $\beta$ treatment for 1 hour prior to collection. Genes were selected if they were consistently differentially regulated in the same direction in all 3 cell lines. Using the paired analysis strategy, we identified 41 genes that were consistently upregulated and 16 that were consistently downregulated in response to TGF- $\beta$ treatment (Supplemental Table 1). Real-time PCR validation was performed using a common pool of genes selected from both experiments with T $\beta$ RII (WKO;PY), T $\beta$ RII ${ }^{(\mathrm{fl} / \mathrm{fl} ; \mathrm{PY})}, \mathrm{T} \beta \mathrm{RII}{ }^{(\mathrm{WKO} ; \mathrm{PY})}$ plus TGF- $\beta$, and T $\beta$ RII ${ }^{(\mathrm{fl} / \mathrm{fl} ; \mathrm{PY})}$ plus TGF- $\beta$ samples.

We observed significant differences $(P<0.05)$ in the expression of 11 genes identified by microarray in the T $\beta \mathrm{RII}(\mathrm{WKO}$;PY) and $\mathrm{T} \beta \mathrm{RII}(\mathrm{fl} / \mathrm{fl} ; \mathrm{PY})$ dataset using real-time PCR analyses (Table 1, top; clustered in Supplemental Figure 1A). Among these 11 genes, one $(J u n b)$ was in fact identified in the real-time PCR experiment, but it did not meet the filtering criteria for our $\mathrm{T} \beta \mathrm{RII} \mathrm{I}^{(\mathrm{fl} / \mathrm{fl} ; \mathrm{PY})}$ versus $\mathrm{T} \beta \mathrm{RII}{ }^{(\mathrm{WKO} ; \mathrm{PY})}$ microarray analyses. This suggested that our conservative filtering approach likely excluded some genes that were 
Table 1

$T \beta R I I($ WKo;PY) carcinoma cell gene expression relative to T $\beta$ RII(fl/fl;PY) controls

\begin{tabular}{|c|c|c|}
\hline Gene symbol & Fold change & $P$ \\
\hline \multicolumn{3}{|c|}{ Complete medium } \\
\hline S100a6 & 2.6 & 0.04 \\
\hline Ctsa & 2.4 & 0.03 \\
\hline Bst2 & 2.0 & 0.01 \\
\hline Junb & 1.7 & 0.03 \\
\hline Pdgfb & -1.6 & 0.05 \\
\hline $\operatorname{ltg} b 3$ & -1.9 & 0.02 \\
\hline$T b \times 15$ & -2.1 & 0.05 \\
\hline Tspan7 & -2.5 & 0.01 \\
\hline$F 2 r$ & -2.8 & 0.03 \\
\hline Pcdh21 & -3.6 & 0.003 \\
\hline Vim & -22.3 & 0.03 \\
\hline \multicolumn{3}{|c|}{ Complete medium + TGF- $\beta$} \\
\hline $\mathrm{CxCl1}$ & 14.8 & 0.04 \\
\hline Cxcl5 & 7.6 & 0.03 \\
\hline Bst2 & 2.8 & 0.02 \\
\hline Ctsa & 2.0 & 0.03 \\
\hline$B c / 2 / 11$ & -3.5 & 0.04 \\
\hline Tspan7 & -3.9 & 0.03 \\
\hline$F 2 r$ & -4.1 & 0.008 \\
\hline $\operatorname{ltg} b 3$ & -4.2 & 0.02 \\
\hline Wnt9a & -4.2 & 0.03 \\
\hline$P d g f b$ & -4.8 & 0.001 \\
\hline Pcdh21 & -4.8 & 0.001 \\
\hline Cxcl12 & -5.7 & 0.03 \\
\hline Camk2n1 & -6.2 & 0.03 \\
\hline Ctgf & -6.7 & 0.04 \\
\hline Smad6 & -6.8 & 0.02 \\
\hline Gadd45a & -7.3 & 0.004 \\
\hline Cxcr4 & -8.0 & 0.03 \\
\hline Wisp1 & -10.7 & 0.02 \\
\hline Lmcd1 & -13.4 & 0.03 \\
\hline Vim & -24.4 & 0.02 \\
\hline Serpine1 & -62.5 & 0.01 \\
\hline
\end{tabular}

Real-time PCR validation of differences in gene expression associated

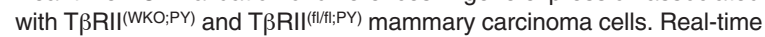
PCR was performed using the biological replicates for each model, and the $1 / \Delta C$ t values were used to determine the significance using 2-tailed, unpaired $t$ tests. Validation was performed using T $\beta R I^{\prime(W K O ; P Y)}$ and $\mathrm{T} \beta \mathrm{R} \mathrm{II}^{(\mathrm{ft} / \mathrm{l} ; \mathrm{PY})}$ mammary carcinoma cells cultured in complete medium. To further stratify the differences between the cell populations and more accurately model the situation likely encountered in vivo, validation was also performed using T $\beta R I^{(\text {WKO;PY) }}$ cells cultured in complete medium compared with $T \beta R \|^{(f / f t / i: P Y)}$ cells cultured in complete medium containing TGF- $\beta$ ligand at $10 \mathrm{ng} / \mathrm{ml} 1$ hour after stimulation. No differences in gene expression were observed when T $\beta R$ IIIKO; PY) cells cultured in complete medium were compared with T $\beta R \|(\mathrm{WKO} ; \mathrm{PY})$ cells cultured in complete medium containing TGF- $\beta$ ligand at $10 \mathrm{ng} / \mathrm{ml} 1$ hour after stimulation. Values were normalized to Gusb, Hprt1, Hsp90ab1, Actb, and Ppia.

differentially regulated; however, for the purpose of determining a gene expression signature, this was preferable. TGF- $\beta$ was present in the complete cell culture medium, but not at a sufficient level to allow detection of downstream Smad pathway activation when comparing serum-free and complete medium conditions. Therefore, to better model the stimulation likely experienced by the carcinoma cells during tumor progression, we also performed validation in the presence of TGF- $\beta$. When samples were stimu- lated with TGF- $\beta$, we were able to detect a significant difference $(P<0.05)$ in the expression of 21 genes using the pooled gene validation approach (Table 1; clustered in Supplemental Figure 1B). Importantly, we identified differences in expression of genes that are known to be TGF- $\beta$-responsive, including Serpine1 (PAI-1), Smad6, Pdgfb, Gadd45a, Ctgf, Lmcd1, and Bcl2l11 (Bim). Notably, Cxcl1, Cxcl5, Bst2, and Csta were significantly upregulated in the T $\beta R I^{(W K O ; P Y)}$ cells when compared with the TGF- $\beta$-treated controls. Previous studies have demonstrated a significant association between $\mathrm{Cxcl} 1$ or $\mathrm{Cxcl} 5$ and lung metastasis $(20,34)$; therefore, we selected these chemokines for further validation.

To determine whether $\mathrm{Cxcl1}$ and $\mathrm{Cxcl5}$ mRNA expression correlated with protein secretion, we performed cytokine antibody array analyses with conditioned medium from the T $\beta \mathrm{RII}(\mathrm{WKO} ; \mathrm{PY})$ and control T $\beta R I^{(\mathrm{fl} / \mathrm{fl} ; \mathrm{PY})}$ cell lines. $\mathrm{Cxcl} 1$ and $\mathrm{Cxcl} 5$ were the only secreted cytokines, of 62 represented on the array, that were consistently differentially regulated when comparing the 2 models (Figure 2A and Supplemental Table 2). The results paralleled those obtained in our real-time PCR validation of the microarray analyses. Previously we have shown that signaling through the Cxcr2 receptor, which is activated by both $\mathrm{Cxcl} 1$ and $\mathrm{Cxcl} 5$, was responsible for part of an enhanced inflammatory cell recruitment observed in association with the T $\beta R \mathrm{RII}^{(\mathrm{WKO} ; \mathrm{PY})}$ tumor microenvironment as compared with

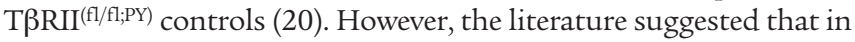
addition to recruitment of inflammatory cell populations, Cxcr2 signaling may enhance the migration of carcinoma cells (35-37). To test this in mammary carcinoma cells, we stimulated the highly metastatic murine 4T1 and human MDA-MB-231 cell lines with Cxcl1 at increasing doses in wound closure assays (Figure 2B). The wound closure results were supported by previous studies demonstrating CXCR2 expression by MDA-MB-231 cells (38-40) and Western blot verification of $\mathrm{Cxcr} 2$ protein production by the $4 \mathrm{~T} 1$ cell line in our laboratory (Figure 2B). Our results indicated that carcinoma cell migration was enhanced in the presence of $\mathrm{Cxcl} 1$ stimulation, thereby providing another potential mechanism for enhanced metastasis when chemokine expression is elevated in vivo.

$T G F-\beta$-responsive genes were identified in $T \beta R I^{(f l / f l p Y)}$ mammary carcinoma cells. Grouped analyses of the microarray results identified genes that differed between the models; however, the genes that differed between the models were not necessarily TGF- $\beta$-responsive genes. Of the genes that we identified as differentially regulated by TGF- $\beta$ (Supplemental Table 1 ), we were able to validate 23 by real-time PCR (Table 2 ). Among the differentially expressed genes that were validated by real-time PCR, Tnfrsf $1 b$ (TNF- $\alpha$ recep-

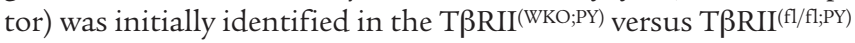
profile. As previously mentioned, this suggested that our conservative approach was effective in filtering genes for our TGF- $\beta$ response signature. We were able to identify, in addition to known TGF- $\beta$ target genes, novel TGF- $\beta$-responsive genes that may play a major role in tumorigenesis. Importantly, the chemokines Cxcl1, $\mathrm{Cxcl5}$, and $\mathrm{Ccl} 20$ were consistently suppressed by TGF- $\beta$. The suppression of chemokine expression by TGF- $\beta$ suggested that loss of TGF- $\beta$ signaling could result in selective enhancement of chemokine expression. These data further substantiated and extended our previous preliminary analyses regarding TGF- $\beta$-dependent regulation of host-tumor interactions associated with differential chemokine expression in vitro and in vivo $(19,20)$.

TGF- $\beta$ suppressed basal and oncostatin $M$-induced Cxcl1, Cxcl5, and Ccl20 expression in established mammary epithelial cell lines. TGF- $\beta$ was able to suppress $\mathrm{Cxcl1}, \mathrm{Cxcl5}$, and $\mathrm{Ccl} 20$ expression in carcinoma 
A
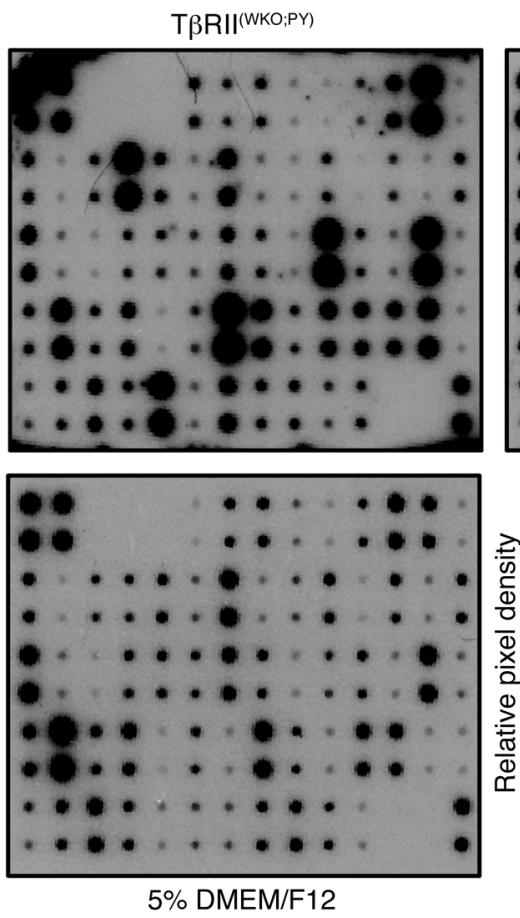

B
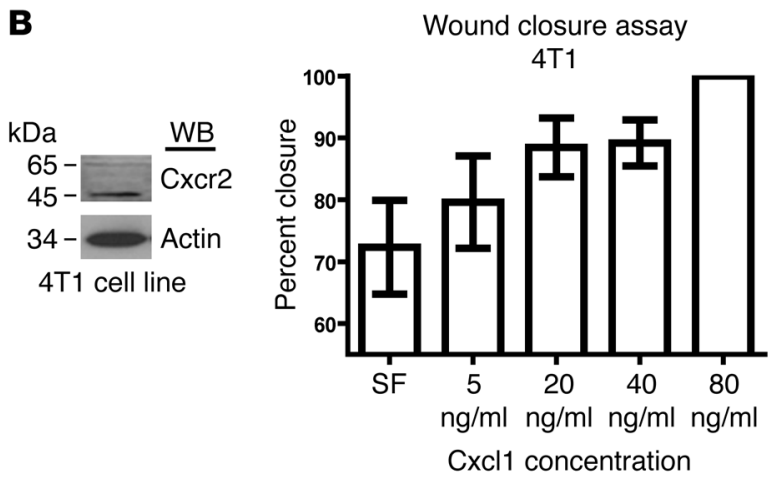

$\mathrm{T} \beta \mathrm{RII} \mathrm{I}^{(\mathrm{fl} / \mathrm{fl} ; \mathrm{PY})}$

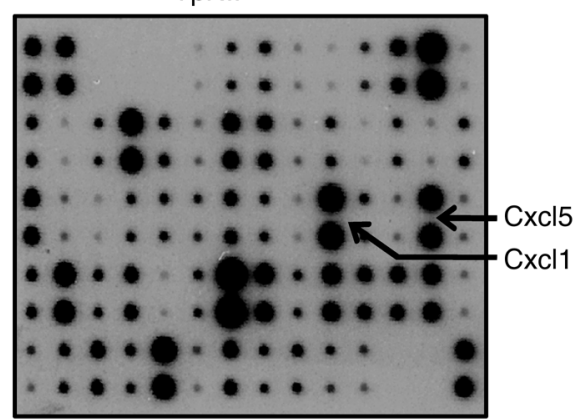

Chemokine protein expression

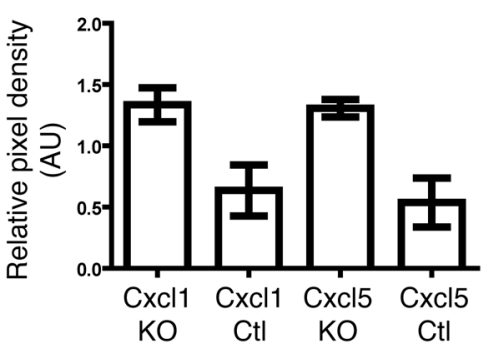

\section{Figure 2}

TGF- $\beta$-dependent chemokine protein secretion by mammary carcinoma cells and the effect of Cxcl1 stimulation on metastatic mammary carcinoma cell migration. (A) Conditioned medium from T $\beta R I /(\mathrm{WKO} ; \mathrm{PY})$ and $T \beta R \mathrm{I}^{(\mathrm{fl} / \mathrm{f} / \mathrm{PY})}$ mammary carcinoma cells revealed increased secretion of $\mathrm{Cxcl} 1$ and $\mathrm{Cxcl} 5$ protein by the T $\beta \mathrm{RII(WKO}$;PY) populations according to cytokine antibody array. Quantitation of $\mathrm{Cxcl} 1$ and $\mathrm{Cxcl5}$ expression was performed and represented as the median transformed mean values $\pm \mathrm{SEM}$. $P<0.05$, T $\beta \mathrm{RII}(\mathrm{WKO} ; \mathrm{PY})(\mathrm{KO})$ vs. T $\beta R \|^{(\mathrm{fl} / \mathrm{fl} / \mathrm{PY})}(\mathrm{Ctl}), 2$-tailed unpaired $t$ test. (B) Wound closure assays were used to determine the effect of Cxcl1 presence on metastatic carcinoma cell migration. Cxcr2 protein production by the 4T1 cell line was observed by Western blot (WB), and the expression of CXCR2 by MDA-MD-231 cells has been previously reported (38-40). Values are reported as mean percentage \pm SEM. For the $4 \mathrm{~T} 1$ carcinoma cell line, $P=0.5018$ at $5 \mathrm{ng} / \mathrm{ml}, P=0.0853$ at $20 \mathrm{ng} / \mathrm{ml}, P=0.0588$ at $40 \mathrm{ng} / \mathrm{ml}, P<0.005$ at $80 \mathrm{ng} / \mathrm{ml}$, 2-tailed unpaired $t$ test. For the MDA-MB-231 cell line: $P=0.0019$ at $5 \mathrm{ng} / \mathrm{ml}, P=0.0411$ at $20 \mathrm{ng} / \mathrm{ml}$, and $P=0.0068$ at $40 \mathrm{ng} / \mathrm{ml}$, 2-tailed, unpaired $t$ test.

cells derived from the MMTV-PyVmT mouse model. However, it was unclear whether this regulation was specific for MMTV$\mathrm{PyVmT}$-driven carcinoma cells or alternatively a general feature of TGF- $\beta$ signaling in mammary epithelial cell populations. Therefore, we selected the nontransformed HC11 and NMuMG cell lines for analysis to address this issue. To stimulate chemokine expression, we selected the oncostatin M (OSM) ligand due to its previously reported ability to upregulate $\mathrm{Cxcl} 1$ and $\mathrm{C} x \mathrm{cl} / 5$ expression without a significant increase in $C c l 2$ expression (41). As opposed to TNF- $\alpha$, a ligand that is known to potently activate NF- $\mathrm{kB}$ and thereby upregulate a large number of chemokines, OSM stimulation was shown to be more selective for regulation of the Cxcl1 and $\mathrm{Cxcl5}$ chemokines that we had identified in our analyses. In addition, the presence of OSM in breast cancer is clinically relevant $(42,43)$. OSM expression has been shown to be present in $66 \%$ of breast tumors (44). Further, immunohistochemical analyses have been used to demonstrate that $35 \%$ of breast carcinomas and $88 \%$ of inflammatory breast cancers express this ligand (43). Inflammatory breast cancer is often highly aggressive and is associated with poor patient prognosis (45).

HC11 cells were responsive to OSM as determined by reduced tritiated thymidine uptake (Supplemental Figure 2) and increased phosphorylation of Stat 3 after stimulation. The HC11 cells were also responsive to TGF- $\beta$ as determined by reduced tritiated thymidine uptake (Supplemental Figure 2) and increased phosphor- 


\section{Table 2}

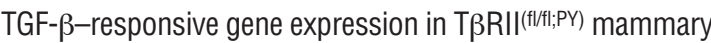
carcinoma cells

\begin{tabular}{|c|c|c|c|}
\hline Gene symbol & FL1 & FL2 & FL3 \\
\hline \multicolumn{4}{|c|}{ Upregulated by TGF- $\beta$} \\
\hline Camk2n1 & 7.3 & 4.7 & 3.3 \\
\hline Cxcl12 & 5.7 & 2.6 & 1.8 \\
\hline Cxcr4 & 3.9 & 3.4 & 1.7 \\
\hline Edn2 & 13.5 & 3.8 & 2.5 \\
\hline Egr2 & 3.1 & 2.7 & 2.0 \\
\hline Egr3 & 4.1 & 2.4 & 1.8 \\
\hline Fosb & 4.3 & 5.4 & 2.2 \\
\hline Foxq1 & 7.8 & 2.6 & 1.7 \\
\hline Gadd45a & 6.1 & 7.8 & 2.8 \\
\hline Gja3 & 6.7 & 8.9 & 3.4 \\
\hline Lmcd1 1 & 26.9 & 3.9 & 5.0 \\
\hline Map3k14 & 15.2 & 3.0 & 2.5 \\
\hline Pdgfb & 2.7 & 3.7 & 2.8 \\
\hline Serpine1 & 12.0 & 16.8 & 8.3 \\
\hline Smad6 & 12.9 & 4.3 & 4.1 \\
\hline Tnfrsf $1 b$ & 3.4 & 3.1 & 1.7 \\
\hline Wisp1 & 3.8 & 4.7 & 2.8 \\
\hline Wnt9a & 3.2 & 3.1 & 2.5 \\
\hline \multicolumn{4}{|c|}{ Downregulated by TGF- $\beta$} \\
\hline Adamts1 & -14.3 & -7.5 & -3.1 \\
\hline Ccl20 & -2.0 & -2.3 & -2.4 \\
\hline Cxcl1 & -33.4 & -2.9 & -9.3 \\
\hline $\mathrm{Cxcl5}$ & -2.0 & -2.0 & -1.7 \\
\hline Epgn & -16.0 & -3.7 & -2.0 \\
\hline
\end{tabular}

Real-time PCR validation of TGF- $\beta$-responsive genes in $T \beta R I^{(t / / f / ; P Y)}$ mammary carcinoma cells. Each column represents $1 / \Delta \mathrm{Ct}$ values associated with an individually derived polyclonal control T $\left.\beta R \|^{(t / / f / ; P Y}\right)$ carcinoma cell line in the presence or absence of TGF- $\beta$ at $10 \mathrm{ng} / \mathrm{ml}$ for 1 hour. Genes that demonstrated the same direction of regulation were reported if all values were 1.5-fold or higher with a 2.0-fold or greater change in 2 of 3 of the cell lines. Values were normalized to Gusb, Hprt1, Hsp90ab1, Actb and Ppia.

ylation of Smad2 after stimulation. Importantly, TGF- $\beta$ had no effect on OSM-induced Stat 3 phosphorylation, and OSM had no effect on TGF- $\beta$-dependent Smad 2 phosphorylation. In HC11 cells, TGF- $\beta$ and OSM treatment for 1 hour in vitro had a significant effect on Cxcl1 expression (Figure 3A). In response to TGF- $\beta$ for 1 hour, $C x c l 1$ expression was significantly decreased in HC11 cells. OSM treatment for 1 hour resulted in a significant upregulation of Cxcl1 expression. Importantly, TGF- $\beta$ treatment significantly attenuated the effect of OSM with regard to regulation of Cxcl1 expression. The results in HC11 cells were similar for Cxcl5 (Figure 3C) and Ccl20 (Figure 3E). The NMuMG monoclonal cell line that we have used for analysis responded well to TGF- $\beta$ with regard to growth inhibition, induction of EMT, and Smad2 phosphorylation. However, this clone did not respond to OSM stimulation with a growth response or Stat 3 activation. Accordingly, TGF- $\beta$ treatment for 1 hour significantly decreased the expression of $\mathrm{Cxcl1}, \mathrm{Cxcl5}$, and $\mathrm{Ccl} 20$ in the NMuMG cell line, and OSM had no significant effect (Figure 3, B, D, and F). To determine whether the observed regulation of $\mathrm{Cxcl1}, \mathrm{Cxcl5}$, and Ccl20 was selective, or alternatively a general chemokine effect, we analyzed the expression of $\mathrm{Ccl} 5$ in response to TGF- $\beta$ and OSM stimulation. Ccl5 mRNA was expressed by both cell lines; however, no significant differences were observed in response to TGF- $\beta$, OSM, or both ligands together (Figure 3 , G and H; HC11 and NMuMG, respectively).

The T $\beta R I I^{(W K O ; P Y)}$ gene expression signature correlated with reduced RFS in buman breast cancer. To determine the impact of our gene expression signatures in human breast cancer, we initially compared our $\mathrm{T} \beta \mathrm{RII}{ }^{(\mathrm{WKO} ; \mathrm{PY})}$ and TGF- $\beta$-treated gene expression signatures to the profiles obtained from 4 previously published datasets (22-28). The detailed clinical data from these studies were previously published, and the clinical data pertinent to this study are summarized in Supplemental Tables 3 and 4. Briefly, the Ivshina dataset in this study included 249 unselected breast cancer patients from Sweden, $34 \%$ with $\mathrm{LN}^{+}$and $86 \%$ with $\mathrm{ER}^{+}$tumors. The Loi dataset included 414 breast cancer patients from the United Kingdom and Sweden, 36\% with $\mathrm{LN}^{+}$and $89 \%$ with $\mathrm{ER}^{+}$tumors, with $\mathrm{LN}$ stage and ER characteristics similar to those in the Ivshina dataset. The van de Vijver dataset included 295 patients from The Netherlands, $49 \%$ with $\mathrm{LN}^{+}$and $76 \%$ with $\mathrm{ER}^{+}$tumors. The University of North Carolina (UNC) dataset included 361 patents, $57 \%$ with $\mathrm{LN}^{+}$and $56 \%$ with $\mathrm{ER}^{+}$tumors, being the population with the worst prognosis compared with the other 3 studies based on $\mathrm{LN}$ stage and number of $\mathrm{ER}^{+}$tumors. In individual analyses of the 4 datasets, the Ivshina dataset revealed a correlation with reduced RFS when tumors had a gene profile similar to the T $\beta$ RII(WKO;PY) signature (Supplemental Figures 3 and 4). Compared with the others, this dataset was characterized by a high number of $\mathrm{ER}^{+}$ tumors, and the majority of patients with $\mathrm{LN}^{-}$disease did not receive systemic adjuvant therapy (Supplemental Table 3). In addition, clinical information regarding metastasis-free survival (MFS) was available for 2 of the 4 datasets (van de Vijver and Loi). Patients in the van de Vijver dataset with gene profiles correlating with the T $\beta$ RII ${ }^{(\mathrm{fl} / \mathrm{fl} ; \mathrm{PY})}$ plus TGF- $\beta$ treatment signature had significantly worse MFS than those without the correlation, whereas no significant difference in MFS in association with the signatures was observed for the Loi dataset (Supplemental Figure 5). The correlation was probably due to the high number of ER-positive and $\mathrm{LN}$-positive patients who did not receive adjuvant endocrine therapy in the van de Vijver dataset and further suggested that the effect of TGF- $\beta$ signaling may differ depending on the context of ER status, LN status, and distant metastases.

Therefore, to further extend and increase the power of our subset analyses, we subsequently combined the 4 independent datasets and examined the association of our T $\beta$ RII(WKO;PY) and TGF- $\beta$-treated T $\beta$ RII ${ }^{(\mathrm{f} / / \mathrm{fl} ; \mathrm{PY})}$ carcinoma cell signatures with tumor subtype and RFS. There was total of 1,319 human breast cancer tumor samples in the combined dataset, and the RFS was chosen as the survival parameter because the data were available in all 4 datasets (Figure 4A). The analyses revealed that the $\mathrm{T} \beta \mathrm{RII}(\mathrm{WKO}$;P) carcinoma signature positively correlated with a reduced 10-year RFS (Figure 4A, left). In contrast, a significant difference in RFS was not observed when the TGF- $\beta$ treatment signature was used for correlation (Figure 4A, right). Multivariate analyses were conducted for the 2 TGF- $\beta$-associated signatures, ER status, tumor size, node status, 3 treatment variables, and 4 patient cohorts (using the Ivshina cohort as a reference) using the multivariate Cox model with spline because of the nonlinear property of the signature (Supplemental Tables 4 and 5 and Supplemental Figure 10). The analyses showed that the $\mathrm{T} \beta \mathrm{RII} \mathrm{I}^{(\mathrm{WKO} ; \mathrm{PY})}$ signature was highly significant as an independent prognostic marker of survival $(P=0.015$, second tertile hazard 

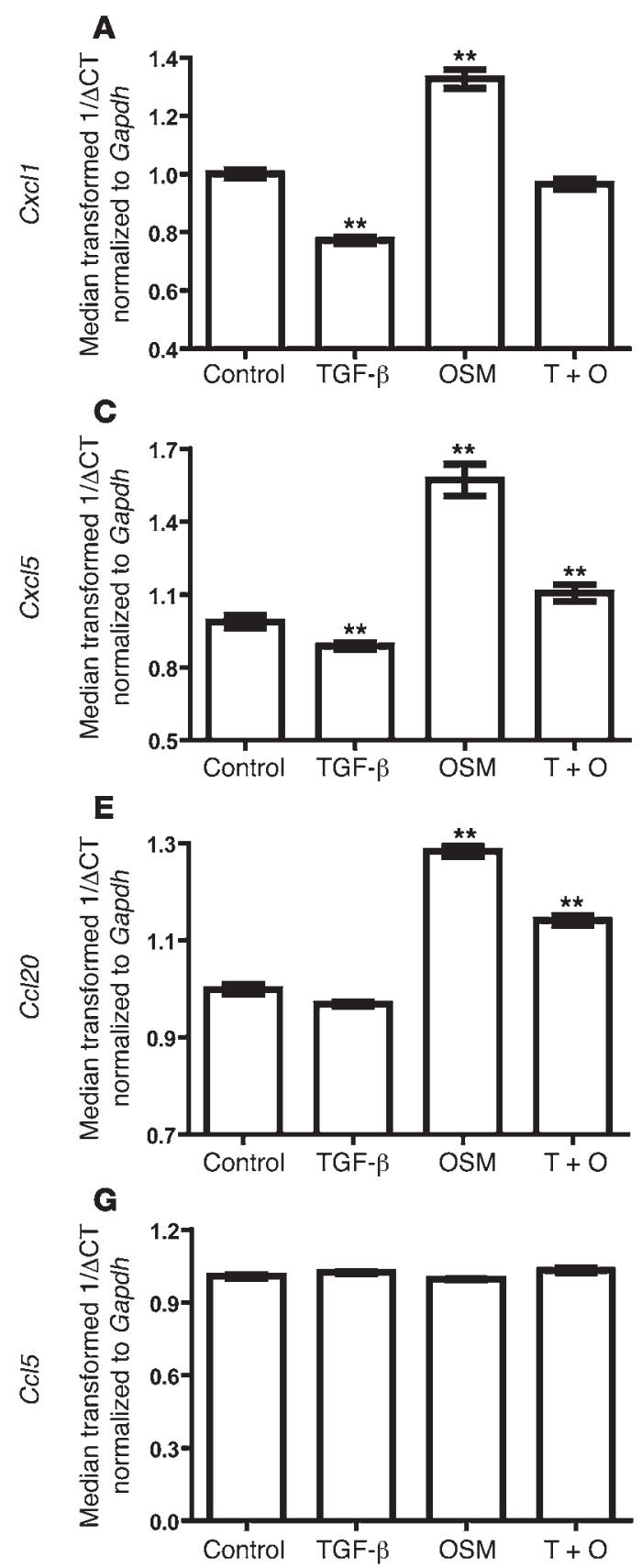

B

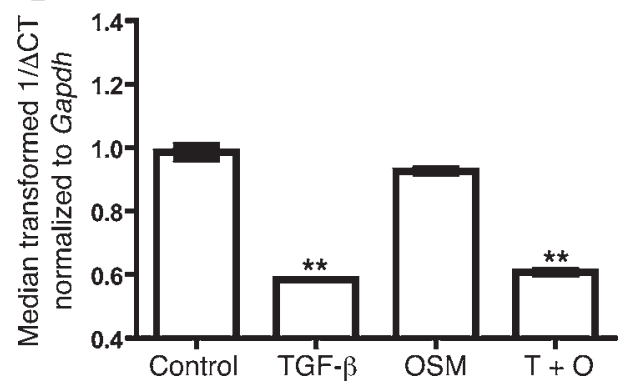

D

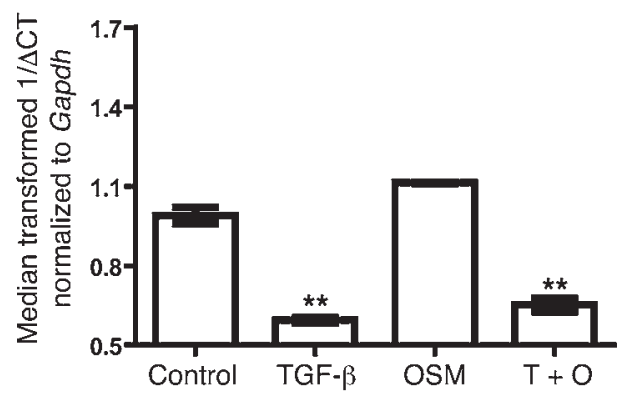

$\mathbf{F}$

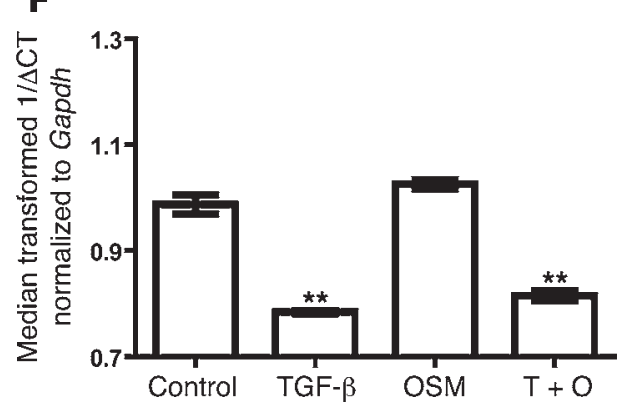

H

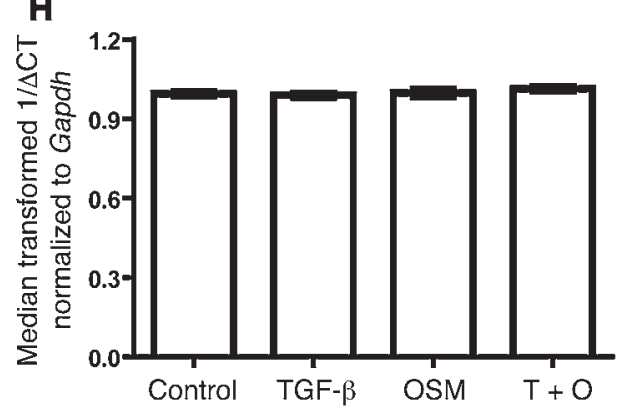

Figure 3

TGF- $\beta$ attenuated basal and OSM-induced expression of $\mathrm{Cxc} / 1, \mathrm{CxC} / 5$, and $\mathrm{Ccl} 20$ in mammary epithelium. TGF- $\beta(10 \mathrm{ng} / \mathrm{ml})$ and OSM (100 ng/ml) stimulation was performed for 1 hour in vitro. Real-time PCR was performed using $\mathrm{HC}_{11}$ (A, C, $\mathbf{E}$, and $\mathbf{G}$ ) and NMuMG (B, D, F, and $\mathbf{H}$ ) cell lines. The median transformed $1 / \Delta C t$ values are reported as mean \pm SEM. TGF- $\beta$ significantly decreased $\mathrm{CxCl1}$ and $\mathrm{Cxc} / 5$ expression in $\mathrm{HC} 11$ and $\mathrm{CxCl}, \mathrm{CxCl} 5$, and Ccl20 in NMuMG cells $(\mathbf{A}-\mathbf{F})$. In the OSM-responsive $\mathrm{HC} 11$ cell line, OSM significantly upregulated $\mathrm{Cxc} / 1$, Cxc/5, and Cc/20 expression (A, C, and E). TGF- $\beta$ significantly attenuated the effect of OSM with regard to $\mathrm{Cxc} / 1, \mathrm{Cxc} / 5$, and $\mathrm{Ccl} 20$ expression in the $\mathrm{HC} 11$ cell line. The NMuMG cell line, which did not respond to OSM in growth response assays or analysis of phospho-Stat3 by Western blot, did not demonstrate chemokine regulation by OSM (B, $\mathbf{D}$, and $\mathbf{F}$ ). $\mathrm{Cc} / 5$ expression was not altered by TGF- $\beta$ or OSM treatment in the $\mathrm{HC} 11$ or NMuMG cell lines ( $\mathbf{G}$ and $\mathbf{H}$, respectively). ${ }^{* \star} P<0.05$. $\mathrm{T}+\mathrm{O}$, combined administration of TGF- $\beta$ and OSM. ratio $1.29,95 \% \mathrm{CI}, 1.07-1.56$, and third tertile hazard ratio 1.16 , 95\% CI, 0.89-1.52, using first tertile as a reference).

In further subset analyses, a strong positive correlation between the T $\beta$ RII(WKO;PY) signature and reduced RFS was observed in the patients with positive LNs (Figure 4B, left), whereas the TGF- $\beta$ treatment signature did not correlate with a difference (Figure 4B, right). No significant difference was observed for either signature in $\mathrm{LN}^{-}$patients (Figure $4 \mathrm{C}$ ), suggesting that abrogation of TGF- $\beta$ signaling may be more relevant in $\mathrm{LN}$ metastasis. We further stratified the data based on primary tumor size at the time of diagnosis (Supplemental Figure 6, A and B); however, no significant correlation with survival was observed for either signature.

Importantly, we observed a significant correlation between the $\mathrm{T} \beta \mathrm{RII}(\mathrm{WKO} ; \mathrm{PY})$ signature and reduced ten year survival in human
$\mathrm{ER}+$ breast cancer (Figure $5 \mathrm{~A}$, left). In the human luminal $\mathrm{A}$ group, which are $\mathrm{ER}^{+}$tumors, our T $\beta \mathrm{RII}(\mathrm{WKO}$;PY) signature significantly correlated with a reduction in 10-year RFS (Figure 5B, left). A significant correlation was not observed with regard to survival for either signature in association with treatment with adjuvant hormonal therapy alone; human luminal B tumors; $\mathrm{ER}^{-}$tumors; or lack of treatment with a systemic adjuvant chemotherapy (Figure 5C and Supplemental Figure 7, A-C, respectively). RFS in the basal and Her2 breast cancer subtype patient populations did not significantly correlate with either signature (Supplemental Figure 8, A and B). Together, our results suggest that TGF- $\beta$ signaling may interact with the ER signaling network to regulate tumor recurrence and metastasis during human breast cancer progression. 
A

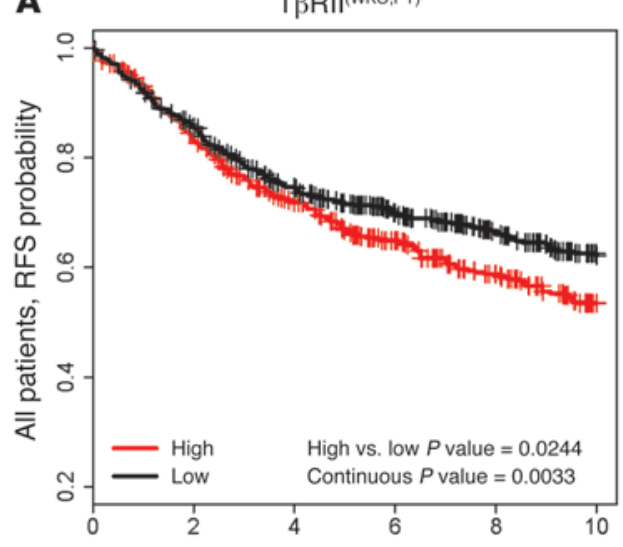

B

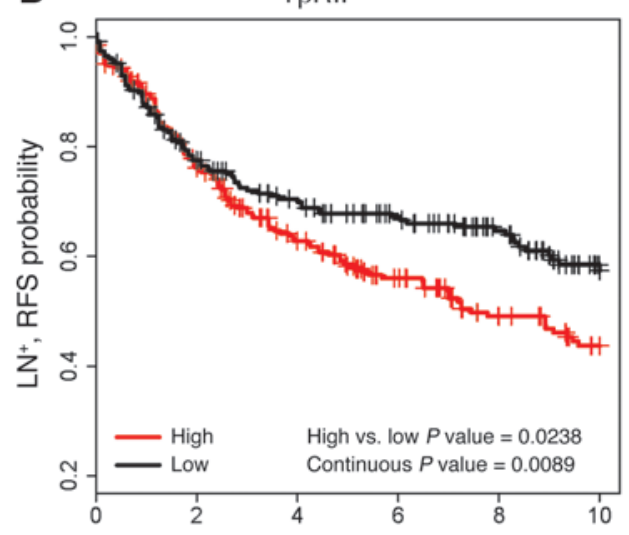

C

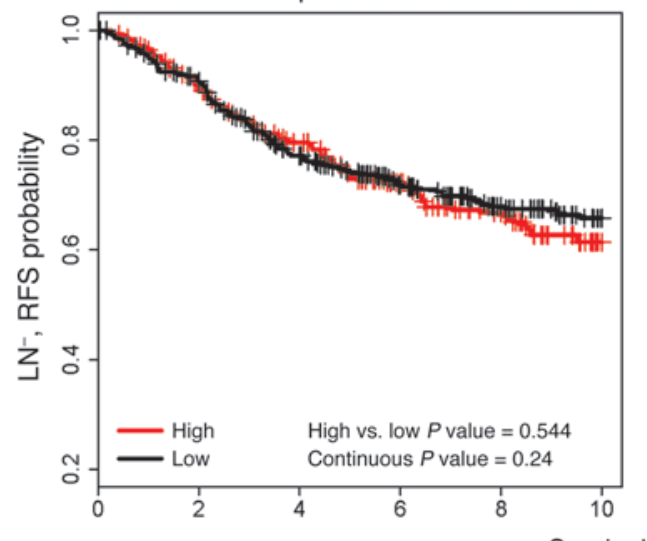

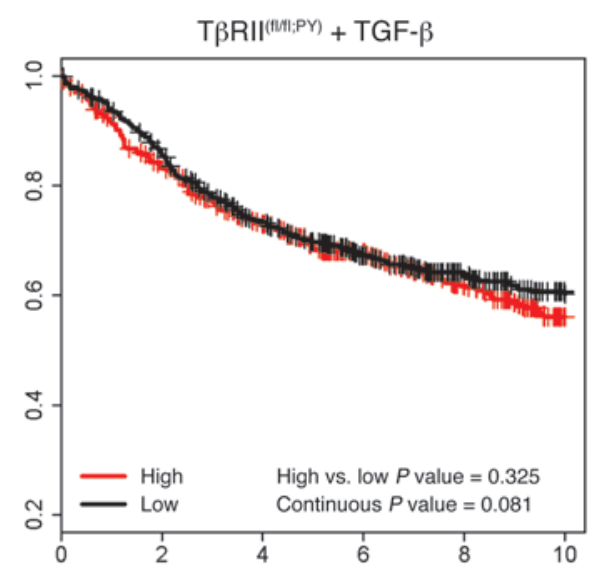
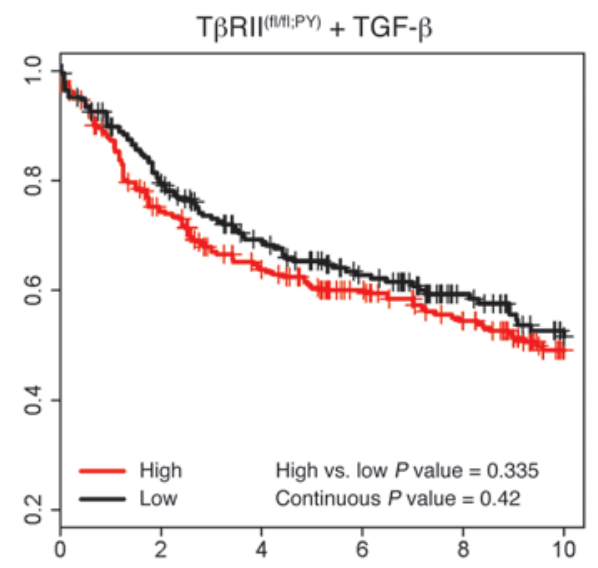

T $\beta$ RIII(Mn:PY) + TGF- $\beta$

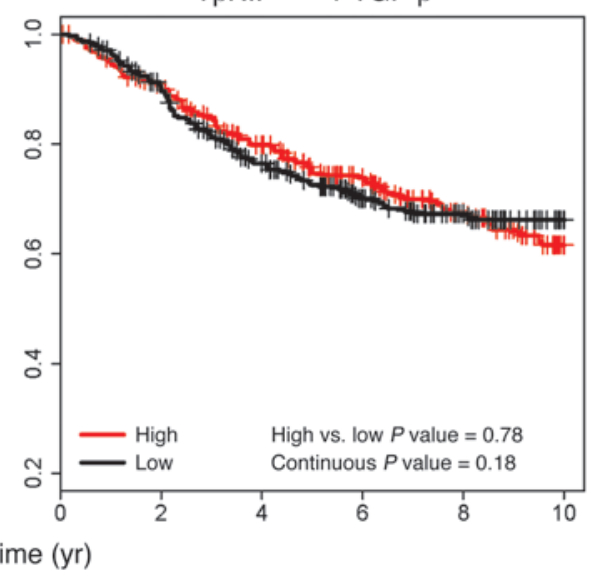

\section{Figure 4}

Loss of TGF- $\beta$ signaling in mammary carcinoma cells resulted in a signature that correlated with increased risk of relapse during human breast cancer progression. (A) The TGF- $\beta$ signature correlation with breast cancer RFS in all patients. T $\beta R$ II(WKO;PY) and T $\beta R \|^{(f / f t \mid P Y)}$ mammary carcinoma gene expression signatures were compared with profiles from 1,319 human breast cancer tissues. The $T \beta R I /(W K O ; P Y)$ and $T \beta R I^{(f / / f t ; P Y)}$ plus TGF- $\beta$ treatment signatures were also used to determine the correlation with RFS (left and right columns, respectively). The T $\beta R \|^{(\mathrm{WKO} ; \mathrm{PY})}$ signature significantly correlated with decreased RFS. No significant difference in RFS was observed in correlation with the TGF- $\beta$ treatment gene expression signature. (B) In human $\mathrm{LN}^{+}$breast cancer patients, the TRRII(WKO;PY) signature correlated with reduced RFS (left), whereas the TGF- $\beta$ treatment signature did not have a significant correlation (right). (C) In LN- patients, no significant correlations were observed. Red, high correlation $(r>0)$; black, low correlation $(r<0)$. The "high versus low" model is based on transforming the TGF- $\beta$ signature correlation into a dichotomous variable (high: $r>0$; low: $r<0$ ), and the "continuous" model uses the untransformed correlation as a continuous variable. Association of these groups with RFS was evaluated with the log-rank test.

\section{Discussion}

TGF- $\beta$ is a well-known regulator of tumor progression and metastasis; however, it remains unclear how TGF- $\beta$ actually regulates these processes. In early work, the focus of TGF- $\beta$ signaling was on the tumor cell, and a large amount of data supported an early tumor-suppressive role for TGF- $\beta$ in this context. However, it was also shown that TGF- $\beta$ signaling within the carcinoma cell could promote tumor progression and metastasis. This dual role for TGF- $\beta$ signaling has been referred to as the TGF- $\beta$ paradox, and it is not known how TGF- $\beta$ signaling switches from tumor suppressor to tumor promoter. However, our recent work demonstrating the recruitment of metastasis-enhancing bone marrow-derived cells to the tumor microenvironment could help explain this paradox. In addition to TGF- $\beta$ signaling within the tumor cell, strong experimental evidence has also shown that an excess of secreted TGF- $\beta$ could promote tumor progression. In our T $\beta$ RII(WKO;PY) model of mammary carcinoma cell-specific TGF- $\beta$ signaling deficiency, we observed a role for TGF- $\beta$ as a suppressor of tumor initiation, progression, and metastasis. We observed differences in overall tumor burden, apoptosis, interaction with the adjacent fibrovascular stroma, angiogenesis, tumor cell heterogeneity, and inflammation involving bone marrow-derived myeloid cell populations $(19,20)$. However, due to the complexity of the compound phenotype, it was difficult to assess the molecular mechanisms of 
A

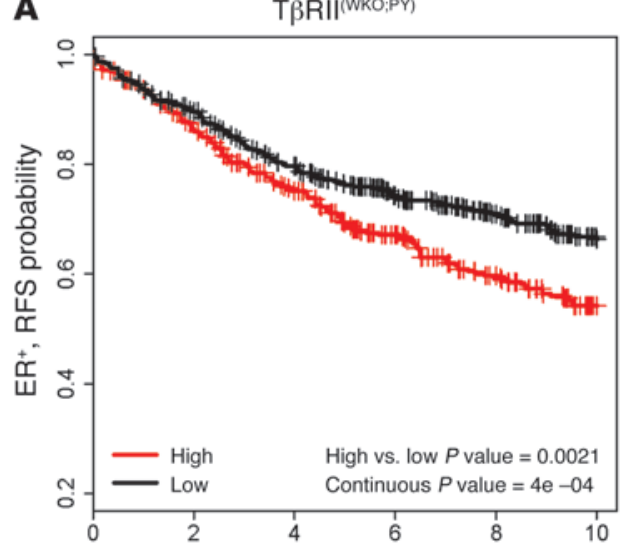

B

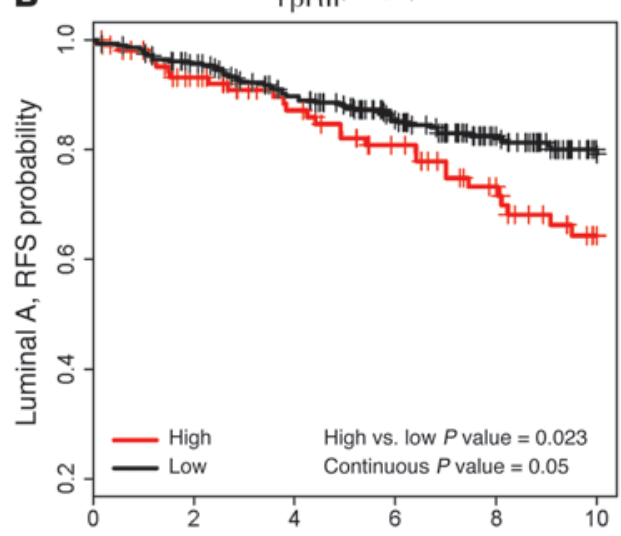

C

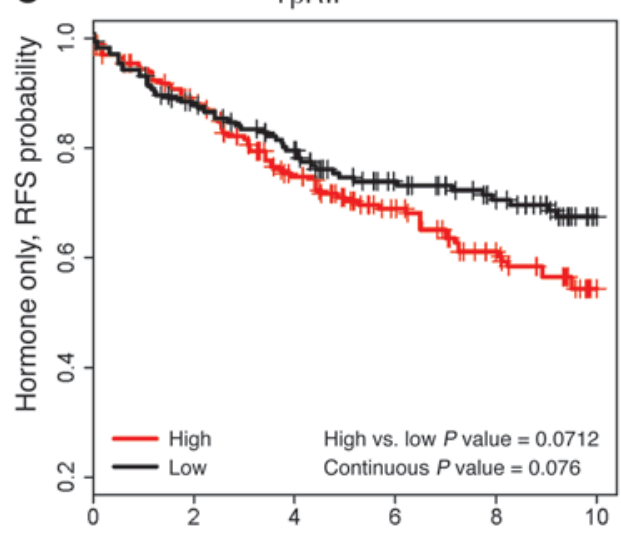

T $\beta$ RIII(N/P):Pn) + TGF- $\beta$

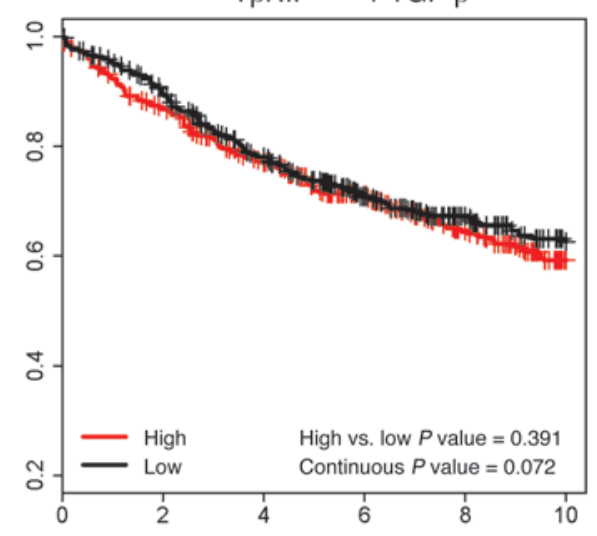

$T \beta R I^{(1(n): P Y)}+T G F-\beta$

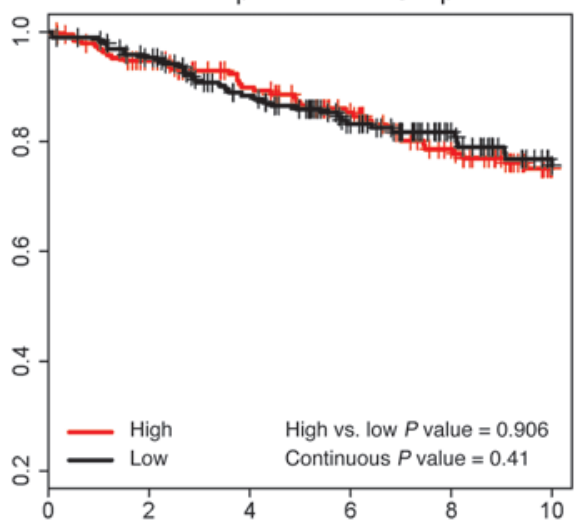

$T \beta R I^{(\text {IfIt:PY) }}+T G F-\beta$

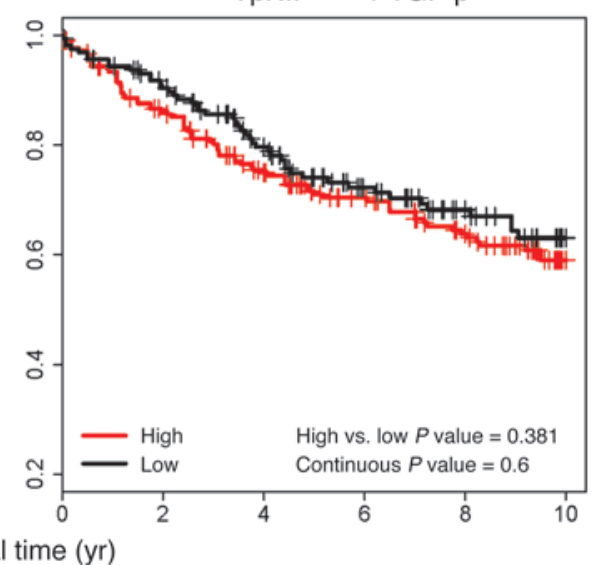

Figure 5

Loss of TGF- $\beta$ signaling in mammary carcinoma cells resulted in a signature that may further differentiate ER-positive tumors and risk of relapse in breast cancer patients. Increased risk of poor RFS when human $\mathrm{ER}^{+}$and luminal $\mathrm{A}$ breast cancer (A and B, respectively; left) was associated with a TGF- $\beta$ signaling-deficient mammary carcinoma cell gene expression signature. The TGF- $\beta$ treatment signature did not correlate with a difference in RFS ( $\mathbf{A}$ and $\mathbf{B}$, right). Although a trend toward reduced RFS was present when the T $\beta$ RII(WKO;PY) signature was associated with hormone only-treated breast cancer (C), neither signature was statistically significant. Red, high correlation $(r>0)$; black, low correlation $(r<0)$. Association of these groups with RFS was evaluated with the log-rank test.
TGF- $\beta$ signaling within the carcinoma cells that ultimately regulated the observed effects. Therefore, we established polyclonal carcinoma cell lines from our primary tumor tissues in order to more precisely determine the molecular differences between the $\mathrm{T} \beta \mathrm{RII} \mathrm{I}^{(\mathrm{WKKO} ; \mathrm{PY})}$ and T $\beta \mathrm{RII} \mathrm{I}^{(\mathrm{fl} / \mathrm{fl} ; \mathrm{PY})}$ models.

We subjected the carcinoma cells to microarray analyses and identified a relatively small number of genes that were differentially regulated when the $\mathrm{T} \beta \mathrm{RII} \mathrm{I}^{(\mathrm{WKO} ; \mathrm{PY})}$ and $\mathrm{T} \beta \mathrm{RII} \mathrm{I}^{(\mathrm{fl} / \mathrm{fl} ; \mathrm{PY})}$ models were compared. Within this subset of genes, some of those we identified were previously described TGF- $\beta$-responsive target genes. The identification of previously described TGF- $\beta$-responsive genes in this analysis further substantiated the validity of our approach.
Importantly, we were able to identify many genes that were differentially regulated between the two models that had not been previously reported. In addition, we were able to identify genes that were TGF- $\beta$-responsive within 1 hour of stimulation. Together, these results provide an initial step toward identification of the essential molecular details related to mechanisms, including regulation of chemokine expression, that mediate TGF- $\beta$-dependent control of tumor progression and metastasis in vivo.

Our previous work has shown that TGF- $\beta$ within the carcinoma cell can regulate adjacent stromal-epithelial and host-tumor interactions within the tumor microenvironment $(19,20)$. In addition, our previously reported results and preliminary gene expres- 
sion data suggested that the chemokines Cxcl1, Cxcl5, and Ccl20 were regulated by TGF- $\beta$ in mammary carcinoma cells $(19,20)$. Functionally, we were able to demonstrate that signaling through Cxcr2, a common receptor for $\mathrm{Cxcl} 1$ and $\mathrm{Cxcl5}$, was responsible for a significantly greater proportion of the enhanced immature bone marrow-derived myeloid cell (myeloid immune suppressor cell $[\mathrm{MISC}])$ recruitment to the T $\beta \mathrm{RII} \mathrm{I}^{(\mathrm{WKO} ; \mathrm{PY})}$ compared with the $\mathrm{T} \beta \mathrm{RII} \mathrm{I}^{(\mathrm{fl} / \mathrm{fl} ; \mathrm{PY})}$ tumor microenvironment (20). In our current study, we have been able to demonstrate that these gene products are consistently suppressed by TGF- $\beta$ in multiple independently derived $\mathrm{T} \beta \mathrm{RII}{ }^{(\mathrm{f} / \mathrm{fl} ; \mathrm{PY})}$ mammary carcinoma cell lines. Suppression of $\mathrm{Cxcl1}$, $\mathrm{Cxcl5}$, and $\mathrm{Ccl} 20$ expression upon TGF- $\beta$ stimulation proved to be a key feature distinguishing the T $\beta \mathrm{RII}(\mathrm{WKO} ; \mathrm{PY})$ and T $\beta \mathrm{RII} \mathrm{I}^{(\mathrm{fl} / \mathrm{fl} ; \mathrm{PY})}$ models. We have also been able to determine that the regulation of this chemokine subset by TGF- $\beta$ is not specific for the MMTV-PyVmT transformed cell populations. In the nontransformed HC11 and NMuMG mammary epithelial cell lines, TGF- $\beta$ significantly suppressed $C x c l 1, C x c l 5$, and $C c l 20$ expression. In the absence of TGF- $\beta$ treatment, OSM stimulation increased the expression of these chemokines. Since the presence of OSM is clinically relevant in breast cancer (42-44), the link we have identified with TGF- $\beta$ signaling is likely important. Specifically, it has been shown that a majority of inflammatory breast cancers express this ligand (43), and our current results suggest that TGF- $\beta$ - and OSM-dependent chemokine production may have a functional role in the regulation of this type of breast cancer that is often aggressive and associated with poor patient prognosis (45). Further, Cxcl1 expression was recently correlated with a metastasis gene expression signature in human breast cancer (46). Together, the data suggest that TGF- $\beta$ can suppress basal and OSM-induced Cxcl1, Cxcl5, and Ccl20 expression in nontransformed mammary epithelium and in carcinoma cells, thereby regulating inflammation that is known to promote tumor progression and metastasis.

The power of molecular profiling has been highlighted in recent years, since it has been shown to effectively predict for breast tumor subtypes and RFS over time (8, 9, 21-27). According to the literature, many of the genes that we identified in this study may have a significant role in the regulation of tumor progression and metastasis (Supplemental Table 1). However, the literature at the level of gene-by-gene analysis often lacks the ability to predict interactions between signaling networks that ultimately regulate the process of tumor progression and metastasis in vivo. Further, it is not feasible to concurrently upregulate roughly 200 genes and downregulate 70 others in a single cell to experimentally model the compound interacting pathways in vivo. Therefore, we compared the gene expression signatures obtained in our current study with the individual profiles obtained in 4 previously described human breast cancer datasets representing 1,319 breast cancer patients (22-28). The patient data included tumor subtype classification, size, LN status, ER status, treatment regimen, and survival over a 10 -year period. Importantly, we were able to determine that the $T \beta R I^{(W K O ; P Y)}$ signature predicted for reduced RFS in the entire dataset and in subsets including $\mathrm{ER}^{+}$, luminal $\mathrm{A}$, or $\mathrm{LN}^{+}$patients. Notably, our TGF- $\beta$ treatment gene expression signature did not predict for a difference in RFS in any of the correlate analyses that we conducted (Figures 4 and 5 and Supplemental Figures $4-8)$. This demonstrated that there are clear biological differences between complete abrogation of TGF- $\beta$ signaling and enhanced TGF- $\beta$ stimulation. Our study and statistical models have limitations related to combining biologically and clinically heteroge- neous datasets, and further studies are required to reveal the exact mechanism of ER and TGF- $\beta$ pathway interactions. However, our results and those recently reported by Padua et al. (6) suggest that abrogation and stimulation of TGF- $\beta$ signaling correlate with poor prognosis in human $\mathrm{ER}^{+}$and $\mathrm{ER}^{-}$breast cancer, respectively (Supplemental Figure 9).

In summary, we have now been able to identify significant molecular differences in mammary carcinoma cells lacking the ability to respond to TGF- $\beta$ when compared with mammary carcinoma cells that are capable of a TGF- $\beta$ response. The molecular signatures suggested that intrinsic, stromal-epithelial, and host-tumor interactions together mediate tumor progression and metastasis as a result of the tumor cell response to TGF- $\beta$ stimulation. Further, at the time of diagnosis in human breast cancer, if a molecular signature that resembles the carcinoma cell-specific TGF- $\beta$ signaling deficiency is detected in luminal A subtype and $\mathrm{ER}^{+}$tumors, the corresponding patients may benefit from an aggressive postoperative treatment regimen to increase their chance for RFS.

\section{Methods}

Cell line derivation and culturing conditions. $\mathrm{PyVmT}$ carcinoma cell lines were derived from T $\beta R I^{(\mathrm{WKO} ; \mathrm{PY})}$ and $\mathrm{T} \beta \mathrm{RII} \mathrm{I}^{(\mathrm{fl} / \mathrm{fl} \mathrm{PY})}$ primary tumors, established and cultured in DMEM/F12 with 5\% adult bovine serum as previously described (19). The NMuMG cell line has been previously described (28). NMuMG cells were cultured in DMEM with $10 \%$ FCS and $150 \mu \mathrm{l}$ insulin per $500 \mathrm{ml}$ of medium. HC11 cells were a gift from Jeffery Rosen (Baylor College of Medicine, Houston, Texas, USA) on behalf of Bernd Groner (Georg-Speyer-Haus, Institute for Biomedical Research, Frankfurt am Main, Germany) and were grown in RPMI 1640 medium containing $10 \%$ bovine calf serum, $5 \mathrm{mg} / \mathrm{ml}$ insulin (Sigma-Aldrich), $10 \mathrm{ng} / \mathrm{ml} \mathrm{EGF}$ (Sigma), $2 \mathrm{mM}$ L-glutamine, $100 \mathrm{U} / \mathrm{ml}$ penicillin, and $100 \mathrm{mg} / \mathrm{ml}$ streptomycin. Medium was changed 23 hours before collection for microarray and real-time PCR analyses. One hour before collection, the medium was aspirated, and complete medium or complete medium containing TGF- $\beta$ was added to the cells. Cell lines were approximately $70 \%$ confluent at the time of RNA isolation. Chemokine expression studies were carried out in the presence or absence of $10 \mathrm{ng} / \mathrm{ml} \mathrm{TGF}-\beta$ or $100 \mathrm{ng} / \mathrm{ml} \mathrm{OSM}$ that was added 1 hour prior to RNA isolation as indicated.

Analysis of DNA recombination. Southern blots were performed as previously described (47). Briefly, DNA was isolated by phenol-chloroform extraction, and $10 \mu \mathrm{g}$ was digested with $B g l I I$ and resolved on a $1 \%$ agarose gel, then transferred to a nylon membrane. The membranes were then prehybridized and hybridized at $65^{\circ} \mathrm{C}$ using a buffer containing $4 \times$ SSC phosphate (SSCP), $1 \times$ Denhardt's solution, $1 \%$ SDS, and $100 \mu \mathrm{g} / \mathrm{ml}$ of sheared salmon sperm DNA with the previously described ${ }^{32} \mathrm{P}$-labeled $3^{\prime}$ probe to detect Tgfbr2 recombination (47).

TGF- $\beta$ growth response analyses. Tritiated thymidine incorporation was performed using $4 \times 10^{4}$ cells that were plated in a 24 -well dish and allowed to grow overnight. The next day, when cells were approximately $50 \%$ confluent, the medium was aspirated and replaced with complete medium or complete medium containing $0.1,1.0$, or $10.0 \mathrm{ng} / \mathrm{ml} \mathrm{TGF-} \beta$. Twenty-two hours later, cells were pulsed with $4 \mu \mathrm{Ci}$ of tritiated thymidine per well (PerkinElmer). After 2 hours, the cells were fixed with $1 \mathrm{ml} 10 \%$ trichloroacetic acid for 30 minutes at room temperature (RT), followed by 2 additional 30 -minute washes with $10 \%$ trichloroacetic acid. DNA was solubilized by incubation in $300 \mu \mathrm{l} 0.2 \mathrm{~N} \mathrm{NaOH}$ for 30 minutes. Radioactivity was counted using $100 \mu \mathrm{l}$ of solubilized DNA in $4 \mathrm{ml}$ scintillation fluid.

HङE staining and immunofluorescence. H\&E staining and immunofluorescence were performed using standard techniques. Briefly, medium was aspirated, and cells were washed with PBS then fixed in 10\% neutral 
buffered formalin for 30 minutes at RT. Cells were washed (twice) with PBS plus $10 \mathrm{mM}$ glycine, then permeabilized PBS plus $0.2 \%$ Triton X-100 for 5 minutes at RT. Slides were washed (twice) with PBS plus $10 \mathrm{mM}$ glycine. Slides were blocked with PBS containing 3\% milk for 10 minutes at RT. Primary antibody (diluted in PBS plus $3 \%$ milk) was added for 30 minutes at RT. Texas red-conjugated phalloidin (T7471; Invitrogen) was used at 1:200 diluted in PBS plus 3\% milk. Slides were washed (3 times) for 5 minutes in PBS and blocked for 3 minutes in $3 \%$ milk. Secondary antibodies were added at 1:800 for 30 minutes in the dark, then washed ( 3 times) for 5 minutes with PBS. Slides were mounted using ProLong Antifade Gold with DAPI (Invitrogen). Texas red-conjugated phalloidin images were displayed in the green channel for the purpose of illustration.

RNA isolation. Cells were grown and treated in T-75 flasks prior to collection. One milliliter of TRIzol per T-75 flask was used to lyse the cells. The lysates were incubated at RT for 5 minutes, then $0.2 \mathrm{ml}$ chloroform was added. The samples were shaken vigorously by hand for 15 seconds, incubated at RT for 3 minutes, and centrifuged at $13,000 \mathrm{~g}$ for 15 minutes at $4^{\circ} \mathrm{C}$. Three hundred microliters from the aqueous phase was removed, and an equal volume of $70 \%$ RNA-free EtOH was added slowly while mixing with a pipette tip to avoid localized precipitation. The samples were loaded into an RNeasy column (QIAGEN) and centrifuged for 30 seconds at 8,000 g. Buffer RW1 $(700 \mu \mathrm{l})$ was added to the column and centrifuged for 30 seconds at $8,000 \mathrm{~g}$. RPE buffer $(500 \mu \mathrm{l})$ was added to the column and centrifuged for 30 seconds at $8,000 \mathrm{~g}$ (twice; column was placed in a new collection tube for the second wash). The column was centrifuged for 1 minute at $8,000 \mathrm{~g}$ to eliminate the remaining buffer. RNA was eluted in a fresh RNase-free microfuge tube using $30 \mu \mathrm{l} \mathrm{RNase}$-free water, then stored at $-80^{\circ} \mathrm{C}$ until use.

Affymetrix DNA microarray and real-time PCR validation. Samples were checked for integrity and subjected to microarray hybridization using the Affymetrix Mouse 4302.0 gene chip according to standard protocols. Briefly, Agilent's Bioanalyzer microfluidic assay (Agilent Technologies) was used to assay RNA integrity. Spectrophotometric and fluorometric methods were combined to quantitate protein and nucleic acids present in the sample and to ensure quality control of each sample. Following quality control, the RNA was prepared for microarray analysis using the GeneChip One-Cycle Target Labeling and Control Reagents kit (Affymetrix). Briefly, $1.5 \mu \mathrm{g}$ of total RNA was reverse transcribed to ds CDNA using an oligo-dT primer coupled to a 77 promoter. In vitro transcription from the ds cDNA was then carried out using $\mathrm{T} 7$ polymerase and incorporating biotin-modified CTP and UTP ribonucleotides. The biotinylated cRNA $(20 \mu \mathrm{g})$ was fragmented and hybridized to an Affymetrix GeneChip Mouse Genome 4302.0 Array containing 45,000 sets of 11 - to 25 -mer oligomers, representing 39,000 mouse transcripts (34,000 are annotated as well-defined genes). Hybridized cRNA was detected using streptavidin coupled to phycoerythrin. GeneChips were scanned using GeneChip Scanner 3000 7G Plus 2 and GeneChip Operating System (GCOS; Affymetrix). Default values were used to grid images (.DAT) and generate .CEL and .CHP files. CEL files (raw Affymetrix data) were transformed by Robust Multichip Analysis (RMA) (48) prior to filtering. Validation for microarray data was conducted using real-time PCR according to the manufacturer's instructions (SuperArray) with a custom template and proprietary primer sets for the reported gene products (custom template CAPM-0439; SuperArray). Genes included for validation from the T $\beta$ RII (WKO;PY) and TGF- $\beta$ treatment signatures were analyzed using T $\beta$ RII(WKO;PY) $T \beta R{ }^{(\text {(WKO;PY) }}$ plus TGF- $\beta(10 \mathrm{ng} / \mathrm{ml})$,

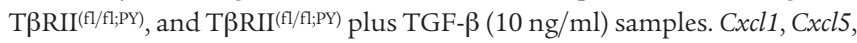
and $\mathrm{Ccl} 20$ expression analyses in HC11 and NMuMG cells were conducted using the primer sets and conditions previously reported (19).

Cytokine antibody array and Western blot analysis. The cytokine antibody array was performed using conditioned medium as previously described (19). Western blots were performed as previously described (19), using
Cxcr2 (SC-7304; Santa Cruz Biotechnology Inc.) and actin (A-2066; SigmaAldrich) primary antibodies and ECL detection (GE Healthcare).

Statistics. Six replicates were performed for thymidine incorporation analyses. Results were reported as the mean $\pm \mathrm{SEM}$, and 2-tailed unpaired $t$ tests were used to determine significance $(P<0.05)$. In the microarray experiment, genes were selected if they met all of the following criteria: signal was up- or downregulated at least 1.5 -fold in all experimental samples when compared with the controls; at least 2 of the 3 experimental samples represented a 2.0-fold or higher change in expression when compared with the controls; and the coefficient of variance $(\mathrm{CV})$ value for the control group was less than 2.0. In grouped analyses, results with a 2 -tailed, unpaired $t$ test $P$ values less than 0.05 were reported as significant. In paired analyses, results were reported if the fold change moved in the same direction for all samples and was at least 1.5 in all 3 samples with at least a 2.0-fold change in 2 of 3 samples. Results for the real-time PCR validation of microarray data were reported as mean of the median transformed $1 / \Delta \mathrm{Ct}$ values \pm SEM. Two-tailed unpaired $t$ tests were used to determine significance, and a $P$ value less than 0.05 was reported as significant. Results for the cytokine array, wound closure assays, and validation of Cxcl1 expression in response to ligand stimulation were reported as mean $\pm \mathrm{SEM}$. Two-tailed unpaired $t$ tests were used to determine significance $(P<0.05)$. Correlative analyses for our gene expression signatures with human gene profiling and clinical status data were performed using normalized data representing 1,319 patients from 4 independent, previously reported studies (Gene Expression Omnibus ID: GSE10886, GSE4922, GSE6532, and GSE2845) (22-28). Probes were median centered across each dataset to minimize platform effects. Gene symbols were assigned using the manufacturer-provided annotation, and duplicate gene symbols were collapsed by averaging within each sample. Breast cancer subtypes were assigned based on a nearest centroid classifier (28). ANOVA was used to test the null hypothesis that the mean correlation to a signature is equal across the breast cancer subtypes. The similarity of each human breast cancer test case to the T $\beta$ RII (WKO;PY) or TGF- $\beta$-treated T $\beta$ RII ${ }^{(\mathrm{f} / \mathrm{fl} / \mathrm{PY})}$ carcinoma cell signatures was computed using Pearson correlation. Correlations were associated with RFS and MFS using the univariate Cox proportional hazard regression model. The "high versus low" model is based on transforming the TGF- $\beta$ signature correlation into a dichotomous variable (high: $r>0$; low: $r<0$ ), and the "continuous" model uses the untransformed correlation as a continuous variable (Figures 4 and 5). Association of these groups with RFS was evaluated with the log-rank test and visualized with Kaplan-Meier plots. The multivariate analysis was performed using the 2 TGF- $\beta$-associated signatures, ER status, tumor size, node status, 3 treatment variables, and 4 patient cohorts (Ivshina cohort as a reference) using the multivariate Cox proportional hazard model with spline. All statistical analyses used a $P$ value cutoff of 0.05 to determine significance. All data analysis for human breast cancer correlation was performed in R (www.r-project.org/).

\section{Acknowledgments}

This work is supported by NIH grants CA085492-06, CA102162, and CA126505 and a grant from the T.J. Martell Foundation (to H.L. Moses); NIH grant CA068485 (to the Vanderbilt Microarray Shared Resource); and a grant from The Robert J. and Helen C. Kleberg Foundation (to C.H. Chung).

Received for publication September 17, 2008, and accepted in revised form March 18, 2009.

Address correspondence to: Harold L. Moses, 698 Preston Research Building, 2220 Pierce Avenue, Nashville, Tennessee 372326838, USA. Phone: (615) 936-1782; Fax: (615) 936-1790; E-mail: hal.moses@vanderbilt.edu. 
1. Gobbi, H., et al. 1999. Transforming growth factorbeta and breast cancer risk in women with mammary epithelial hyperplasia. J. Natl. Cancer Inst. 91:2096-2101.

2. Gobbi, H., et al. 2000. Loss of expression of transforming growth factor beta type II receptor correlates with high tumour grade in human breast in-situ and invasive carcinomas. Histopathology. 36:168-177.

3. Sun, L., et al. 1994. Expression of transforming growth factor beta type II receptor leads to reduced malignancy in human breast cancer MCF-7 cells J. Biol. Chem. 269:26449-26455.

4. Shipitsin, M., et al. 2007. Molecular definition of breast tumor heterogeneity. Cancer Cell. 11:259-273.

5. Ziv, E., Cauley, J., Morin, P.A., Saiz, R., and Browner, W.S. 2001. Association between the T29-->C polymorphism in the transforming growth factor beta 1 gene and breast cancer among elderly white women: The Study of Osteoporotic Fractures. JAMA. 285:2859-2863.

6. Padua, D., et al. 2008. TGFbeta primes breast tumors for lung metastasis seeding through angiopoietin-like 4. Cell. 133:66-77.

7. Wang, S.E., et al. 2008. Transforming growth factor beta engages TACE and ErbB3 to activate phosphatidylinositol-3 kinase/Akt in ErbB2-overexpressing breast cancer and desensitizes cells to trastuzumab. Mol. Cell. Biol. 28:5605-5620.

8. Perou, C.M., et al. 2000. Molecular portraits of human breast tumours. Nature. 406:747-752.

9. Sorlie, T., et al. 2001. Gene expression patterns of breast carcinomas distinguish tumor subclasses with clinical implications. Proc. Natl. Acad. Sci.U. S. A 98:10869-10874.

10. Pierce, D.F., Jr., et al. 1995. Mammary tumor suppression by transforming growth factor beta 1 transgene expression. Proc. Natl. Acad. Sci. U. S. A. 92:4254-4258.

11. Boulanger, C.A., and Smith, G.H. 2001. Reducing mammary cancer risk through premature stem cell senescence. Oncogene. 20:2264-2272.

12. Gorska, A.E., et al. 2003. Transgenic mice expressing a dominant-negative mutant type II transforming growth factor-beta receptor exhibit impaired mammary development and enhanced mammary tumor formation. Am. J. Pathol. 163:1539-1549.

13. Yang, Y.A., et al. 2002. Lifetime exposure to a soluble TGF-beta antagonist protects mice against metastasis without adverse side effects. J. Clin. Invest. 109:1607-1615.

14. Muraoka, R.S., et al. 2003. Increased malignancy of Neu-induced mammary tumors overexpressing active transforming growth factor beta $1 . \mathrm{Mol}$. Cell. Biol. 23:8691-8703.

15. Muraoka-Cook, R.S., et al. 2004. Conditional overexpression of active transforming growth factor beta1 in vivo accelerates metastases of transgenic mammary tumors. Cancer Res. 64:9002-9011.

16. Muraoka-Cook, R.S., et al. 2006. Activated type I
TGFbeta receptor kinase enhances the survival of mammary epithelial cells and accelerates tumor progression. Oncogene. 25:3408-3423.

17. Siegel, P.M., Shu, W., Cardiff, R.D., Muller, W.J., and Massague, J. 2003. Transforming growth factor beta signaling impairs Neu-induced mammary tumorigenesis while promoting pulmonary metastasis. Proc. Natl. Acad. Sci. U. S. A. 100:8430-8435.

18. Forrester, E., et al. 2005. Effect of conditional knockout of the type II TGF-beta receptor gene in mammary epithelia on mammary gland development and polyomavirus middle $\mathrm{T}$ antigen induced tumor formation and metastasis. Cancer Res. 65:2296-2302.

19. Bierie, B., et al. 2008. Transforming growth factorbeta regulates mammary carcinoma cell survival and interaction with the adjacent microenvironment. Cancer Res. 68:1809-1819.

20. Yang, L., et al. 2008. Abrogation of TGF beta signaling in mammary carcinomas recruits Gr- $1+\mathrm{CD} 11 \mathrm{~b}+$ myeloid cells that promote metastasis. Cancer Cell. 13:23-35.

21. Sorlie, T., et al. 2003. Repeated observation of breast tumor subtypes in independent gene expression data sets. Proc. Natl. Acad. Sci. U. S. A. 100:8418-8423.

22. Ivshina, A.V., et al. 2006. Genetic reclassification of histologic grade delineates new clinical subtypes of breast cancer. Cancer Res. 66:10292-10301.

23. Loi, S., et al. 2007. Definition of clinically distinct molecular subtypes in estrogen receptor-positive breast carcinomas through genomic grade. J. Clin. Oncol. 25:1239-1246.

24. Loi, S., et al. 2008. Predicting prognosis using molecular profiling in estrogen receptor-positive breast cancer treated with tamoxifen. BMC Genomics. 9:239.

25. Carroll, J.S., et al. 2006. Genome-wide analysis of estrogen receptor binding sites. Nat. Genet. 38:1289-1297.

26. van 't Veer, L.J., et al. 2002. Gene expression profiling predicts clinical outcome of breast cancer. Nature. 415:530-536

27. van de Vijver, M.J., et al. 2002. A gene-expression signature as a predictor of survival in breast cancer. N. Engl.J. Med. 347:1999-2009.

28. Parker, J.S., et al. 2009. A supervised risk predictor of breast cancer based on intrinsic subtypes. J. Clin. Oncol. 27:1160-1167.

29. Brown, K.A., et al. 2004. Induction by transforming growth factor-beta1 of epithelial to mesenchymal transition is a rare event in vitro. Breast Cancer Res. 6:R215-R231.

30. Oft, M., Akhurst, R.J., and Balmain, A. 2002. Metastasis is driven by sequential elevation of $\mathrm{H}$-ras and Smad2 levels. Nat. Cell Biol. 4:487-494.

31. Oft, M., Heider, K.H., and Beug, H. 1998. TGFbeta signaling is necessary for carcinoma cell invasiveness and metastasis. Curr. Biol. 8:1243-1252.

32. Yang, J., et al. 2004. Twist, a master regulator of morphogenesis, plays an essential role in tumor metastasis. Cell. 117:927-939.

33. Onder, T.T., et al. 2008. Loss of E-cadherin promotes metastasis via multiple downstream transcriptional pathways. Cancer Res. 68:3645-3654.

34. Minn, A.J., et al. 2005. Genes that mediate breast cancer metastasis to lung. Nature. 436:518-524.

35. Kawanishi, H., et al. 2008. Secreted CXCL1 is a potential mediator and marker of the tumor invasion of bladder cancer. Clin. Cancer Res. 14:2579-2587.

36. Warner, K.A., et al. 2008. Endothelial cells enhance tumor cell invasion through a crosstalk mediated by CXC chemokine signaling. Neoplasia. 10:131-139.

37. Li, A., Varney, M.L., and Singh, R.K. 2004. Constitutive expression of growth regulated oncogene (gro) in human colon carcinoma cells with different metastatic potential and its role in regulating their metastatic phenotype. Clin. Exp. Metastasis. 21:571-579.

38. Muller, A., et al. 2001. Involvement of chemokine receptors in breast cancer metastasis. Nature. 410:50-56.

39. Salcedo, R., Martins-Green, M., Gertz, B., Oppenheim, J.J., and Murphy, W.J. 2002. Combined administration of antibodies to human interleukin 8 and epidermal growth factor receptor results in increased antimetastatic effects on human breast carcinoma xenografts. Clin. Cancer Res. 8:2655-2665.

40. Mierke, C.T., et al. 2008. Breakdown of the endothelial barrier function in tumor cell transmigration. Biophys. J. 94:2832-2846.

41. Lafontant, P.J., et al. 2006. Oncostatin M differentially regulates CXC chemokines in mouse cardiac fibroblasts. Am. J. Physiol. Cell Physiol. 291:C18-C26.

42. Jorcyk, C.L., Holzer, R.G., and Ryan, R.E. 2006. Oncostatin $\mathrm{M}$ induces cell detachment and enhances the metastatic capacity of T-47D human breast carcinoma cells. Cytokine. 33:323-336.

43. Holzer, R.G., Ryan, R.E., Tommack, M., Schlekeway, E., and Jorcyk, C.L. 2004. Oncostatin M stimulates the detachment of a reservoir of invasive mammary carcinoma cells: role of cyclooxygenase-2. Clin. Exp. Metastasis. 21:167-176.

44. Crichton, M.B., Nichols, J.E., Zhao, Y., Bulun, S.E., and Simpson, E.R. 1996. Expression of transcripts of interleukin- 6 and related cytokines by human breast tumors, breast cancer cells, and adipose stromal cells. Mol. Cell. Endocrinol. 118:215-220.

45. Lopez, M.J., and Porter, K.A. 1996. Inflammatory breast cancer. Surg. Clin. North Am. 76:411-429.

46. Minn, A.J., et al. 2005. Distinct organ-specific metastatic potential of individual breast cancer cells and primary tumors. J. Clin. Invest. 115:44-55.

47. Chytil, A., Magnuson, M.A., Wright, C.V., and Moses, H.L. 2002. Conditional inactivation of the TGF-beta type II receptor using Cre:Lox. Genesis. 32:73-75.

48. Irizarry, R.A., et al. 2003. Exploration, normalization, and summaries of high density oligonucleotide array probe level data. Biostatistics. 4:249-264. 